This manuscript is a preprint and has been submitted for publication. Please note that this manuscript has yet to undergo peer review. Subsequent versions of this manuscript may therefore have slightly different content. If accepted, the final version of this manuscript will be available via the 'Peer-reviewed Publication DOI' link on the righthand side of this webpage. Please feel free to contact the author.

\title{
Citizen science reveals the population exposure to air pollution
}

Meysman F.J. R. ${ }^{1,2}$, De Craemer S. ${ }^{1}$, Lefebvre W. ${ }^{3}$, Vercauteren J.. ${ }^{4}$, Sluydts V. ${ }^{1}$, Dons. E. ${ }^{5}$, Hooyberghs H. ${ }^{3}$, Van den Bossche J. ${ }^{1}$, Trimpeneers E. ${ }^{6}$, Fierens F. ${ }^{6}$, Huyse H. ${ }^{7}$

${ }^{1}$ Department of Biology, University of Antwerp, Universiteitsplein 1, 2610 Wilrijk

(Antwerpen), Belgium

${ }^{2}$ Department of Biotechnology, Delft University of Technology, Van der Maasweg 9, 2629

HZ Delft, The Netherlands

${ }^{3}$ VITO, Boeretang 200, $2400 \mathrm{Mol}$, Belgium

${ }^{4}$ VMM Vlaamse Milieumaatschappij, Kronenburgstraat 45, 2000 Antwerpen, Belgium

${ }^{5}$ Centre for Environmental Sciences, Hasselt University, Martelarenlaan 42, 3500 Hasselt, Belgium

${ }^{6}$ Belgian Interregional Environment Agency, Gaucheretstraat 92-94, 1030 Brussels, Belgium

${ }^{7}$ Hoger Instituut voor de Arbeid, KU Leuven, 3000 Leuven, Belgium 


\section{Referenced summary paragraph}

Air pollution remains a key environmental problem in an increasingly urbanized world ${ }^{1,2}$. To quantify health impacts and support informed policies, the population exposure needs to be accurately monitored. However, the inherent spatial variability of air quality poses a tenacious challenge to this. While concentrations of traffic-related pollutants like nitrogen dioxide $\left(\mathrm{NO}_{2}\right)$ are known to vary over short distances $^{3,4}$, official monitoring networks remain inherently sparse, as reference stations are costly to construct and operate ${ }^{5,6}$. Here we show that citizen science provides an cost-effective way to collect large, spatially distributed datasets that critically complement official monitoring. The CurieuzeNeuzen project engaged $\mathbf{2 0 . 0 0 0}$ citizens across a large European metropolitan region to measure $\mathrm{NO}_{2}$ concentrations in front of their house using a low-cost sampler design. The resulting dataset reveals the granular structure of air quality with unprecedented detail, and demonstrates that citizen-derived $\mathrm{NO}_{2}$ data possess suitable quality and spatial representativeness, so they can be used to directly quantify the exceedance of legal thresholds, to critically assess and improve the performance of air quality models, and reliably estimate static and dynamic population exposure. These results illustrate how large-scale citizenbased monitoring can directly contribute to better informed policy decisions about challenging environmental problems.

\section{Main text}

\section{Introduction}

Outdoor air pollution is associated with acute health impacts caused by short-term exposure as well as chronic diseases following long-term exposure ${ }^{1,2}$. To support informed policy decisions, national and supra-national legislation requires the population exposure to be quantitatively determined for a set of key air pollutants. To this end, environmental protection agencies (EPAs) implement similar monitoring strategies, in which pollutant concentrations are tracked at high temporal resolution at fixed reference stations ${ }^{5,7}$. Such monitoring is highly resource intensive ${ }^{6}$, and hence reference networks remain spatially sparse. At the same time, for traffic-related pollutants like $\mathrm{NO}_{2}$, the data from fixed stations are only representative of a small surrounding area, particularly in urban environments and near roads, where traffic-related pollutants can show steep concentration gradients over tens to hundreds of meters ${ }^{3-5,8}$. 
To address key questions like "how many people live in an area exceeding legal threshold concentrations?", data from reference monitoring stations are combined with GISbased spatial interpolation, land use regression approaches or atmospheric dispersion modelling 9,10 . These models produce simulated air quality maps, which are used in policy planning and epidemiological studies to infer long-term residential exposure and health impacts ${ }^{11}$. Yet, a critically unresolved problem with such approaches is the lack of detailed spatial model validation. To assess their reliability, simulated air quality maps need to be groundtruthed with a suitably large set of external measurements that are collected in a spatially representative way ${ }^{12}$. This remains a challenging problem, as remote sensing approaches by satellites can determine the total column concentrations of certain air pollutants, but have difficulty to accurately assess concentrations at the ground level or at small spatial scales ${ }^{13}$.

Here we present the results of the citizen science project CurieuzeNeuzen, which has quantified the spatial variation of $\mathrm{NO}_{2}$ at high resolution across Flanders, one of the most urbanized, industrialized and densely populated regions in Europe. The resulting dataset allows a direct empirical assessment of residential exposure, and enables a detailed groundtruthing and subsequent improvement of air quality models. This shows how massscale citizen science offers an innovative way to generate new insights in the spatial structure of air pollution.

\section{The campaign}

The CurieuzeNeuzen project was co-created by academic researchers (providing scientific guidance), volunteer professionals recruited at a local rock festival (providing critical skills in web design, database analysis, IT, product development, and graphics), EPA officials (sharing air quality monitoring expertise) and journalists from a national newspaper (bringing in communication expertise). The project's societal aim was to inform participants and general public about the drivers of air pollution, and create broad-scale awareness about the value of clean air. The scientific goal was to obtain a dataset that allows groundtruthing of the ATMO-Street air quality mode ${ }^{14}$, which is the state-of-the-art tool used for policy support in Flanders (area $13.625 \mathrm{~km}^{2}$; total population 6.5 million; population density 485 inhabitants $\mathrm{km}^{-2}$ ). To obtain sufficient statistical power, we set an ambitious target for citizen-based data collection: 20.000 sampling kits were prepared upfront for distribution ( $\sim 1 \%$ of all households in Flanders), thus allowing a dense spatial coverage of measurement locations $\left(\sim 1.5\right.$ sites on average per $\left.\mathrm{km}^{2}\right)$.

To attract the required number of participants, a multi-channel nation-wide communication campaign was launched (see Methods), using advertisements in magazines, 
newspapers, social media, as well as commercials on radio, TV and movie theatres, and out-of-home advertising on public transport (Fig.1a,b; Extended Movie 1). This communication purposely targeted broad-scale recruitment across all layers of society, thus achieving participation beyond the "usual suspects" of highly educated, environmentallyaware citizens. The communication campaign achieved wide brand recognition $(49 \%$ of the general population could identify the name and objective of the project; see Methods), and the project received wide coverage in national media, stimulated by the large scale of citizen involvement. This resulted in abundant web-based subscriptions during the 4 week recruitment period (Fig.1c,d) providing 52.630 candidate participants (Fig.1e; Extended Data Table 1). Scientifically, this surplus of candidate participants was beneficial, as it allowed targeted site selection for the purpose of model validation by means of a custom-built algorithm (Methods), ensuring a suitable geographical distribution, a higher coverage in urban areas due to stronger spatial variation of $\mathrm{NO}_{2}$, and a representative selection between different emission environments (rural, traffic-affected and street canyon locations). Sampler kits were supplied to individual citizens $(90.2 \%)$, schools (3.9\%), companies and social organizations $(3.4 \%)$ and municipalities $(2.5 \%)$, thus stimulating community participation (Extended Data Table 1).

The ambition to combine high-quality data collection with large-scale citizen participation imposed clear constraints on the project's execution. One challenge was to develop an accurate and reliable protocol for $\mathrm{NO}_{2}$ sensing, yet simple enough to be operated and understood by the broad public (Extended Data Fig. 1). Low-cost electrochemical sensors are increasingly integrated into air quality projects and online platforms ${ }^{15,16}$, but struggle with important selectivity and stability issues for $\mathrm{NO}_{2}\left(\right.$ ref $\left.^{17}\right)$. Additionally, DIY sensors selectively appeal to a technology-oriented public ${ }^{18}$, thus hampering broad citizen participation. Therefore, we deliberately opted for passive samplers ${ }^{19}$, which provide a robust and cost-effective method to measure ambient $\mathrm{NO}_{2}$ concentrations ${ }^{20}$. An additional advantage is that the measurement principle of passive samplers is easy to explain in layman's terms, thus facilitating low-threshold participation. An unforeseen, though favourable outcome was that the measurement kit was widely adopted in classrooms for STEM education (784 schools participated, representing $6.6 \%$ of all primary and secondary schools in Flanders).

Duplicate passive $\mathrm{NO}_{2}$ samplers were simultaneously deployed by all participants over a 4 week period in May 2018, and showed good precision (root mean square error 1.7 $\mu \mathrm{g} / \mathrm{m}^{3}$ between replicates, relative standard deviation $<5 \%$ ) comparable to previous studies ${ }^{21}$. Participants were instructed to position the samplers in the "nose" of a real estate panel that was attached to a window facing the street (Extended Data Fig. 1b). This 
standardized deployment reduced operator variability inherent to citizen sampling, and ensured comparable air flow and turbulence conditions at each sampler location, thus reducing sampler bias. Additionally, the real estate panels generated street-level visibility of the project and created a community feeling among participants ("together we're conducting a large science experiment"). Out of 20,000 sets distributed, $99 \%$ were returned for analysis, illustrating that participants were highly motivated to obtain results. The path from raw sampler data to final results involved three steps (Methods): data validation (Extended Data Fig. 2), sampler calibration based on co-deployment at 20 EPA reference stations (Extended Data Fig. 3) and normalisation to an annual $\mathrm{NO}_{2}$ value ${ }^{22}$ (Extended Data Fig. 4). After quality control and quality assurance, valid data were retained for $89.4 \%$ of sampling locations (Extended Data Table 2).

\section{Resulting dataset and spatial patterns}

The final dataset was communicated to both participants and the broader public as an online, interactive map (Fig. 2a; www.curieuzeneuzen.be). Annual $\mathrm{NO}_{2}$ displayed a skewed distribution with a mean of $22.8 \mu \mathrm{g} \mathrm{m}^{-3}$ and a long tail towards high concentrations (Fig. 2b). Lowest values were recorded at rural locations with little traffic and far from industrial emission sources (minimum: $10.9 \mathrm{\mu g} \mathrm{m}^{-3}$ ), while highest values occurred in trafficcongested urban street canyons and near traffic lights (maximum: $75.3 \mu \mathrm{g} \mathrm{m}^{-3}$ ). $\mathrm{NO}_{2}$ concentrations remain spatially autocorrelated over a short range of $\sim 100 \mathrm{~m}$, after which the variance only slightly increases (semi-variogram displayed in Fig. 3e). Due to such shortscale variation, large differences were found between neighbouring streets within the same city or village, sometimes even within the same street. Bayesian geostatistical modelling (Methods) provides insight into the emission and dispersal factors that drive spatial variation, revealing that $\mathrm{NO}_{2}$ concentrations vary with street typology, indicative of local street-level emissions, as well as population density and land use, which typify urbanisation and widerarea emissions (Extended Data Table 3; Extended Data Fig. 5). The presence of tall, continuous buildings on both sides of the road reduces the dispersion of the pollutants from traffic sources, and increase concentrations, thus illustrating the importance of street canyon effects $^{23}$. As expected, concentrations decrease when sampling locations are further away from the road side (e.g. when residents have a front garden), while the distance to the emission source also plays on a wider scale. Flanders has one of the densest motorway infrastructures in Europe $\left(6.5 \mathrm{~km}\right.$ per $\left.100 \mathrm{~km}^{2}\right)$, and $\mathrm{NO}_{2}$ values increase with proximity to the motorway. Importantly, in addition to traffic volume, our dataset also shows a significant impact of traffic fluidity. $\mathrm{NO}_{2}$ concentrations systematically increase near signalized 
intersections with idling traffic ${ }^{6}$ and in streets with frequent congestion, thus revealing the crucial impact of emissions from stop-and-go traffic on spatial variation in air quality.

\section{Model-data comparison}

Atmospheric dispersion models are widely used to predict concentrations at locations other than those included in the reference monitoring network, thus producing simulated air quality maps ${ }^{9,14}$. Still, dedicated model validation efforts typically involve only a few tens of data points at most, and these do not capture the full spatial variability of the concentration field ${ }^{24}$. The CurieuzeNeuzen dataset enables far more extensive model groundtruthing. Figure 3 compares the histogram of the measurement data to modelled values on the same locations generated with the ATMO-Street model ${ }^{14}$. The model was run over the same fourweek period as the measurement campaign, using hourly meteorological data, traffic intensities, and air quality data from the reference monitoring stations as input. The model captures the distribution of the data well, but underestimates the $\mathrm{NO}_{2}$ concentration (bias of $4.1 \mathrm{\mu g} \mathrm{m}^{-3}$ ), and shows a slightly increased variation (interdecile range $14.9 \mu \mathrm{g} / \mathrm{m}^{3}$ for measurements and $15.7 \mu \mathrm{g} / \mathrm{m}^{3}$ for the model). Detailed data-model comparison enabled multiple optimisations to the model formulation, including a concealed inaccuracy in the model code, an improved categorisation of street canyons, and the optimisation of the landuse component to estimate background concentrations. As a result, the overall model performance was substantially improved (Fig. 3c-d; Extended Data Table 4), thus illustrating the value of large citizen-derived datasets for model improvement. A comparison of the model-simulated and data-derived semi-variograms (Fig. 3e) reveals the critical importance of street canyon effects in the spatial structure of $\mathrm{NO}_{2}$ pollution ${ }^{23}$. Without incorporating street canyon effects, but still accounting for background and local traffic emissions (ATMOStreet model with only RIO and IFDM modules), the model grossly underestimates the total spatial variability and the characteristic length scale of spatial variation (Fig. 3e). When including street canyon effects (ATMO-Street model with all modules), the model correctly estimates the characteristic distance over which $\mathrm{NO}_{2}$ concentrations vary, but slightly underestimates the total spatial variability as observed in the data (Fig. 3e). Subsequent analysis revealed that the latter resulted from imprecise traffic data, thus highlighting the need for systematic and precise traffic monitoring by local authorities.

\section{Spatial representativeness and exceedance}

Data collection for air policy support crucially depends on the representativeness of the resulting datasets. While Flanders has one of the most dense $\mathrm{NO}_{2}$ reference monitoring networks in the world, these data do not allow to directly estimate population exposure and 
exceedance (Extended data Fig. 7a). The CurieuzeNeuzen dataset is far more extensive, but still certain biases could be introduced during subscription or selection of participants that compromise representativeness. To verify this, we estimated the average $\mathrm{NO}_{2}$ concentration during the measurement period with the ATMO-Street air quality model, at the home sampling location of each participant ( $n=17.886$ data points) as well as at each house in the country $(n=6.093 .814$ individual points, one for each inhabitant in Flanders see Methods). Both frequency distributions are nearly identical (Extended data Fig. 7b), thus demonstrating the representative selection of the CurieuzeNeuzen sampling locations. This allows to estimate residential exposure and exceedance over a whole region exclusively based on empirical data. More than $60 \%$ of the sampling locations have annual $\mathrm{NO}_{2}$ concentrations above $20 \mu \mathrm{g} \mathrm{m}^{-3}$, a threshold above which health impacts first become apparent, while $2.3 \%$ of the locations exceed the WHO guideline value of $40 \mu \mathrm{g} \mathrm{m}^{-3}$ above which health risks are considered inacceptable ${ }^{25}$. As the dataset is the representative, this implies that approximately $2.3 \%$ of the population in Flanders (or $\sim 150,000$ inhabitants) live in a place where the annual $\mathrm{NO}_{2}$ concentration at the front door exceeds the EU legal threshold value. This estimate is 3 times higher than the officially reported population exposure $(\sim 0.8 \%)^{26}$, illustrating the need for scrutiny in the way that population exposure is determined and reported.

Exceedances occur prominently within an urban context, and result from a combination of high background concentrations, intense local traffic and street canyon effects. Typically, concentrations are elevated in the inner city areas compared to the surrounding suburban areas. The highest mean $\mathrm{NO}_{2}$ concentration $\left(38.4 \mathrm{\mu g} \mathrm{m}^{-3}\right)$ and highest exceedance (31.5\% of the sampling locations) were recorded in Antwerp, the largest city in the region (Extended data Fig. 7c), and there is a clear positive correlation between number of inhabitants and the percentage of locations in exceedance (Pearson $r=0.91$; Extended data Fig. 7d). While air quality studies have predominantly focused on urban regions, a prominent finding is that elevated $\mathrm{NO}_{2}$-concentrations and exceedances are not restricted to urban areas. The CurieuzeNeuzen dataset reveals this spatially distributed pattern of exceedance in a detailed way. A quarter of the villages and small cities (inhabitants < 50,000 ) have at least one sampling location in exceedance of the WHO guideline. Exceedances typically occur at crossroads within the village centre, where traffic lights or roundabouts create stop-and-go traffic with associated elevated emissions.

\section{Dynamic exposure}

While static exposure accounts for the concentration at a single location, true individual exposure depends on concentrations encountered in different microenvironments 
throughout the day ${ }^{27,28}$. This dynamic $\mathrm{NO}_{2}$ exposure was evaluated for a subsample of 5.020 participants as the time-weighted exposure at home, the out-of-home location (work, school), and while commuting. The time allocation, coordinates of the out-of-home location, and the method of transport to reach this destination were provided by project participants through questionnaires. In general, the dynamic exposure $\left(24.1 \pm 5.5 \mu \mathrm{g} / \mathrm{m}^{3}\right)$ exceeded the residential exposure $\left(22.8 \pm 6.5 \mu \mathrm{g} / \mathrm{m}^{3}\right)$, but strong variation existed between residents from urban versus non-urban locations (Extended Data Fig. 8a,b). For $64 \%$ of the respondents the dynamic exposure was higher than the residential exposure, particularly for workers living in suburban areas, but commuting to cities. In contrast, urban residents typically attained lower dynamic exposures, as they move away from elevated urban concentrations during the day (Extended Data Fig. 8c). The difference between the residential and dynamic exposure increased with travel time (Extended Data Fig. 8d), confirming that commuting adds to traffic-related air pollution exposure with associated health-related impacts ${ }^{29}$.

\section{Societal impact}

Overall, the CurieuzeNeuzen project demonstrates how mass-scale citizen involvement provides a new source of high-quality, spatially distributed data, allowing an inversion of the traditional approach to air quality monitoring. Conventionally, the temporal variation of air quality is characterized in detail via reference stations, and subsequently, spatial extrapolation occurs via models. Here, we first characterize the air quality in high spatial detail using citizen-based monitoring, and subsequently, we extrapolate in time to obtain annual $\mathrm{NO}_{2}$ values for compliance checking. This approach can be easily replicated in other cities and regions, thus providing a cost-effective and quantitative data resource for local environmental policies.

The active involvement of many participants in air quality research brings also other societal benefits ${ }^{30}$. Detailed socio-environmental impact analysis (Methods) reveals considerable behavioural change among the many direct participants (individual citizens, schools, organisations; 180.000 persons or $3 \%$ of the population), but also catalyzed strong concomitant outreach in secondary circles (friends, family, neighbours, colleagues at work; 430.000 persons or $7 \%$ of the population), as well as substantial impact in the public realm, by stimulating the debate on air quality policy within the mainstream media as well as the political arena (e.g. city councils, national parliament). As such, large-scale citizen science appears to generate environmental awareness in a more efficient way than traditional, smallscale projects, thus innovatively combining scientific progress with societal impact. 


\section{Main references}

1. World Health Organization. Ambient air pollution: A global assessment of exposure and burden of disease. Geneva, Switzerland (2016).

2. Lelieveld, J., et al. Cardiovascular disease burden from ambient air pollution in Europe reassessed using novel hazard ratio functions. Eur. Heart J. 40, 1590-1596 (2019)

3. Cyrys J., et al. Variation of $\mathrm{NO}_{2}$ and $\mathrm{NO}_{x}$ concentrations between and within 36 European study areas: Results from the ESCAPE study. Atmos. Environ. 62, 374390 (2012).

4. Wu, H., Reis, S., Lin, C., Beverland, I. J., \& Heal, M. R. Identifying drivers for the intra-urban spatial variability of airborne particulate matter components and their interrelationships. Atmos. Environ. 112, 306-316 (2015).

5. Vardoulakis, S., Solazzo, E., \& Lumbreras, J. Intra-urban and street scale variability of BTEX, $\mathrm{NO}_{2}$ and $\mathrm{O}_{3}$ in Birmingham, UK: Implications for exposure assessment. Atmos. Environ. 45, 5069-5078 (2011).

6. Lin C., Feng X. \& Heal M. R. (2016) Temporal persistence of intra-urban spatial contrasts in ambient $\mathrm{NO}_{2}, \mathrm{O}_{3}$ and $\mathrm{Ox}$ in Edinburgh, UK. Atmos. Poll. Res., 7, 734-741 (2016).

7. Gulia, S., Shiva Nagendra, S. M., Khare, M., \& Khanna, I. Urban air quality management - A review. Atmos. Poll. Res. 6, 286-304 (2014).

8. Marshall, J. D., Nethery, E. \& Brauer, M. Within-urban variability in ambient air pollution: comparison of estimation methods. Atmos. Environ. 42, 1359-1369 (2008).

9. Jerrett, M. et al. A review and evaluation of intraurban air pollution exposure models. J. Exp. Anal. Env. Epidemiol., 15, 185-204 (2005).

10. Hoek, G. et al. A review of land-use regression models to assessspatial variation of outdoor air pollution. Atmos. Environ. 42, 7561-7578 (2008).

11. Hystad, P., et al. Creating national air pollution models for population exposure assessment in Canada. Env. Health Persp. 119, 1123-1129 (2011).

12. Thunis, $P$. et al. Overview of current regional and local scale air quality modelling practices: Assessment and planning tools in the EU. Env. Sci. Policy 65, 13-21 (2016).

13. Bechle, M. J., Millet, D. B. \& Marshall, J. D. Remote sensing of exposure to $\mathrm{NO}_{2}$ : satellite versus ground-based measurement in a large urban area. Atmos. Environ. 69, 345-353 (2013).

14. Lefebvre, W., et al.. Evaluation of the RIO-IFDM-street canyon model chain. Atmos. Environ. 77, 325-337 (2013). 
15. Kumar, P., et al. The rise of low-cost sensing for managing air pollution in cities. Environ. International 75, 199-205 (2015).

16. Morawska, L., et al. Applications of low-cost sensing technologies for air quality monitoring and exposure assessment: How far have they gone? Environ. International, 116, 286-299 (2018)

17. van Zoest, V., Osei, F. B., Stein, A., \& Hoek, G. Calibration of low-cost $\mathrm{NO}_{2}$ sensors in an urban air quality network. Atmos. Environ. 210, 66-75 (2019).

18. Bonney, R., Phillips, T. B., Ballard, H. L. \& Enck, J. W. Can citizen science enhance public understanding of science? Public Understanding of Science 25, 2-16 (2016).

19. Palmes, E. D., Gunnison, A. F., Dimattio, J., \& Tomczyk, C. Personal sampler for nitrogen dioxide. Am. Ind. Hyg. Ass. J. 37, 570-577 (1976).

20. Dijkema, M. B., et al. A comparison of different approaches to estimate small-scale spatial variation in outdoor $\mathrm{NO}_{2}$ concentrations. Environ. Health Persp. 119, 670-675 (2011).

21. Massey, N., et al. Influence of wind-speed on short-duration $\mathrm{NO}_{2}$ measurements using Palmes and Ogawa passive diffusion samplers, Atmos. Environ. 160, 70-76 (2017).

22. De Craemer, S., et al. Using large-scale $\mathrm{NO}_{2}$ data from citizen science for air quality compliance and policy support. EarthArXiv. doi:10.31223/osf.io/ft7mr. (2020)

23. Vardoulakis, S., Valiantis, M., Milner J. \& ApSimon H. Operational air pollution modelling in the UK - Street canyon applications and challenges, Atmos. Environ., 41, 4622-4637 (2007)

24. Lefebvre, W., et al.. Presentation and evaluation of an integrated model chain to respond to traffic- and health-related policy questions. Env. Mod. Softw. 40, 160-170 (2013).

25. World Health Organization. Health risks of air pollution in Europe - HRAPIE project: Recommendations for concentration-response functions for cost-benefit analysis of particulate matter, ozone and nitrogen dioxide (2013)

26. Vlaamse Milieumaatschappij. Jaarrapport Lucht - Effecten van luchtvervuiling op gezondheid en ecosystemen (2019)

27. Dons, E., et al. Impact of time-activity patterns on person exposure to black carbon. Atmos. Environ. 45, 3594-3602 (2011)

28. Setton, E., et al. The impact of daily mobility on exposure to traffic-related air pollution and health effect estimates. J. Exposure Sci. Env. Epidem. 21, 42-48 (2011)

29. Shafran-Nathan, R., Yuval, I. Levy D. \& Broday M. Exposure estimation errors to nitrogen oxides on a population scale due to daytime activity away from home. Sci. Total Env. 580, 1401-1409 (2017) 
30. Fraisl D. et al. Mapping citizen science contributions to the UN Sustainable Development Goals. Sustainability Science. DOI: 10.1007/s11625-020-00833-7 (2020) 

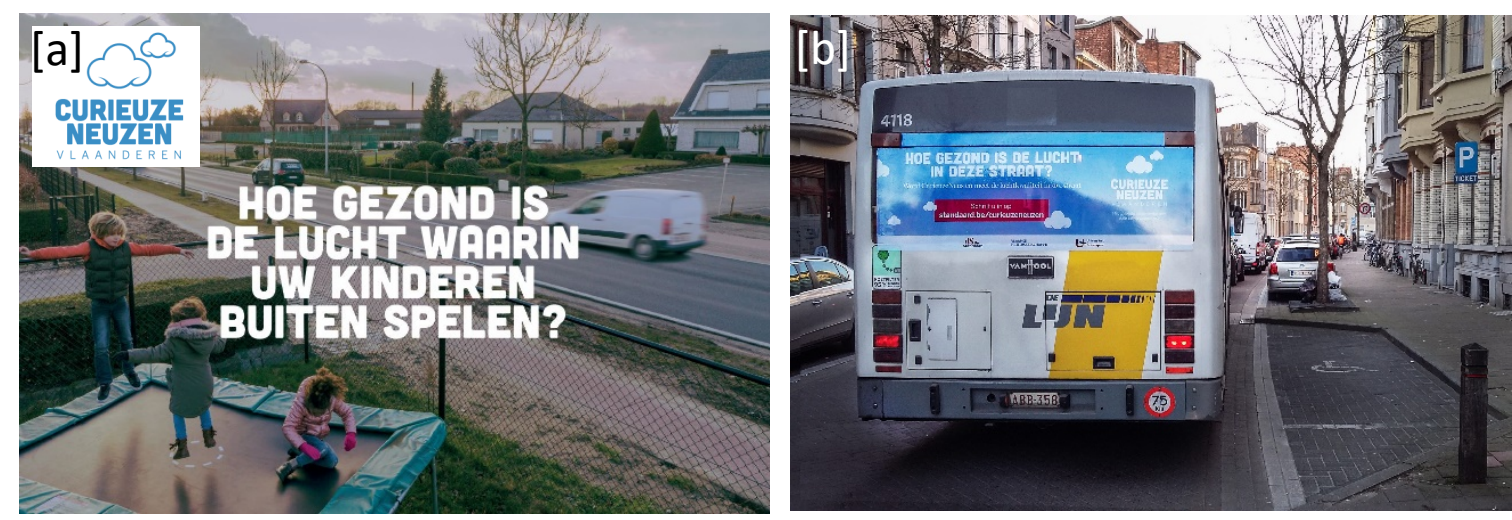

[c]
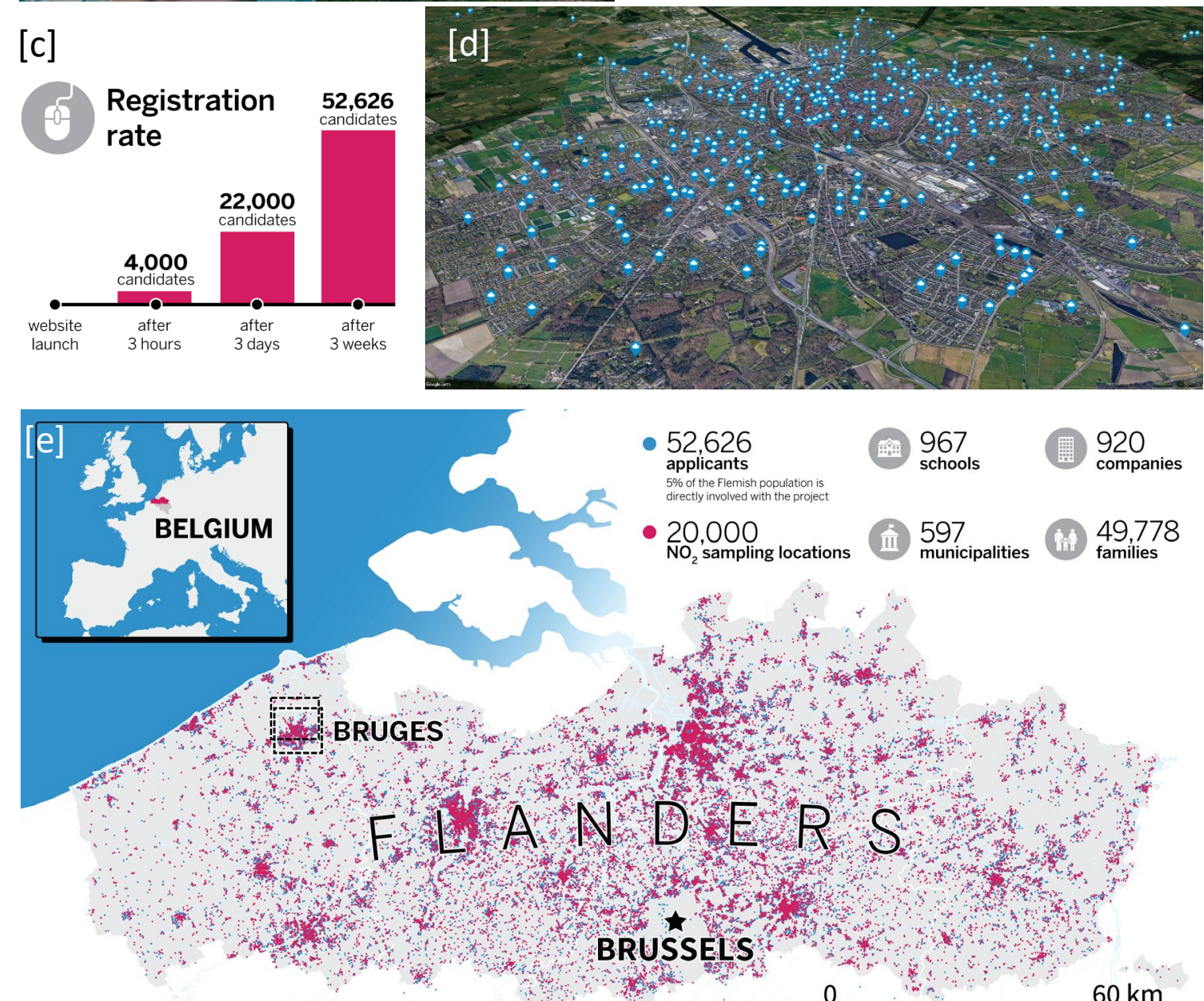

Figure 1. Participant recruitment in the CurieuzeNeuzen citizen science project. [a] The communication campaign focused on everyday activities in ambient air. Example of inprint advertisement in newspapers. [b] Different media-channels were used including out-of-home advertising on buses. [c] Time line of registrations of candidate participants [d] Distribution of sampling locations across the city of Bruges provides an idea of urban coverage [e] Map of Flanders showing spatial distribution of candidate participants (blue markers) and selected sampling locations (red markers). 


\section{$10-1515-2020-2525-30 \quad 30-35 \quad 35-40 \quad 40-45 \mid 45-50 \quad 50-5555-60+60$}

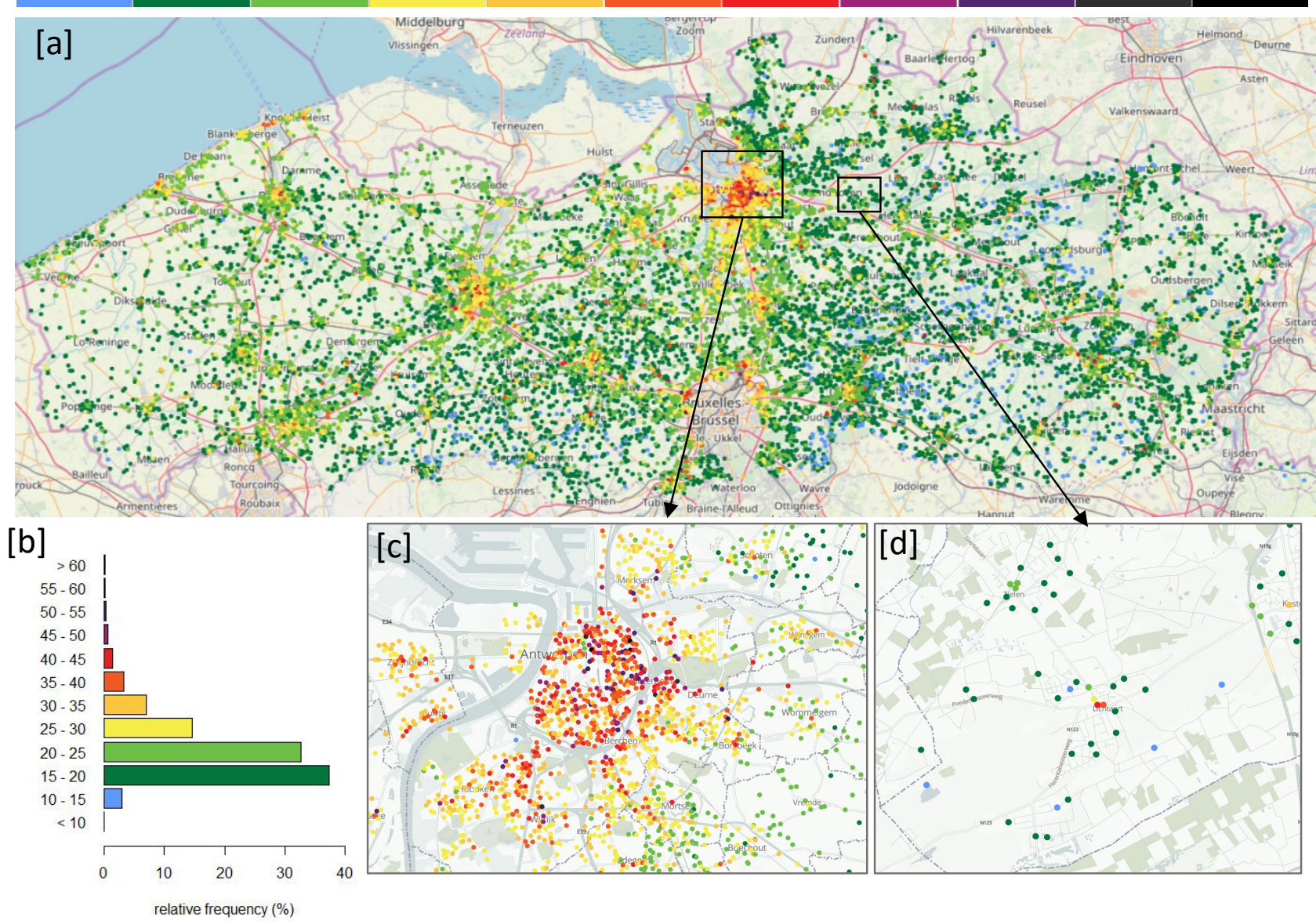

Figure 2. Spatial variation of $\mathrm{NO}_{2}$ concentrations (indicative annual values) as measured in the CurieuzeNeuzen citizen science project. [a] Map of Flanders (@ OpenStreetMap) with colour coded $\mathrm{NO}_{2}$ concentrations in $\mu \mathrm{g} \mathrm{m}^{-3}$ [b] Histogram of all $n=17.886$ validated $\mathrm{NO}_{2}$ concentrations [c] Detailed map showing spatial variation in $\mathrm{NO}_{2}$ at sampling locations across Antwerp, the largest city in Flanders. [d] Detailed map revealing that rural villages also have locations in exceedance of the legal EU limit value. 
Before model-data comparison

[a]

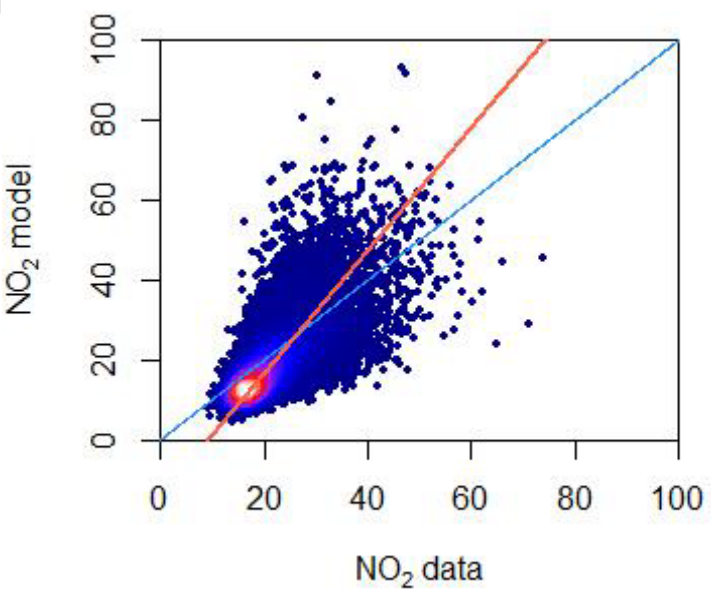

After model-data comparison

[c]

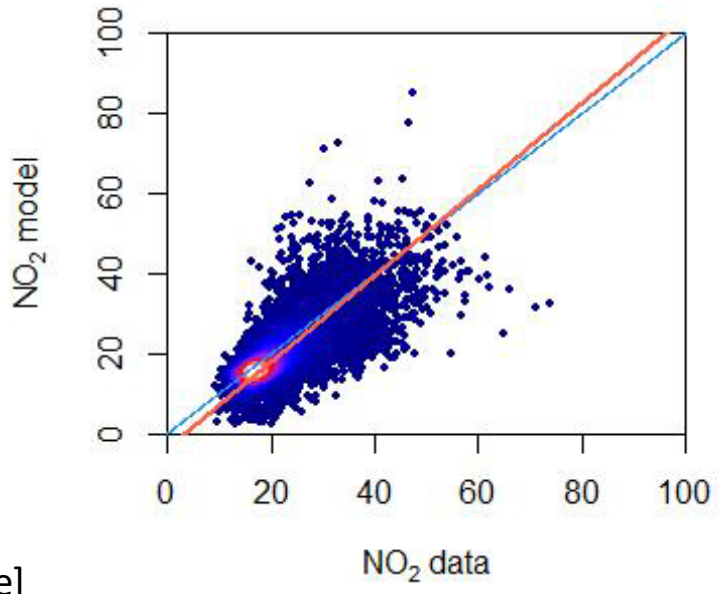

[b]

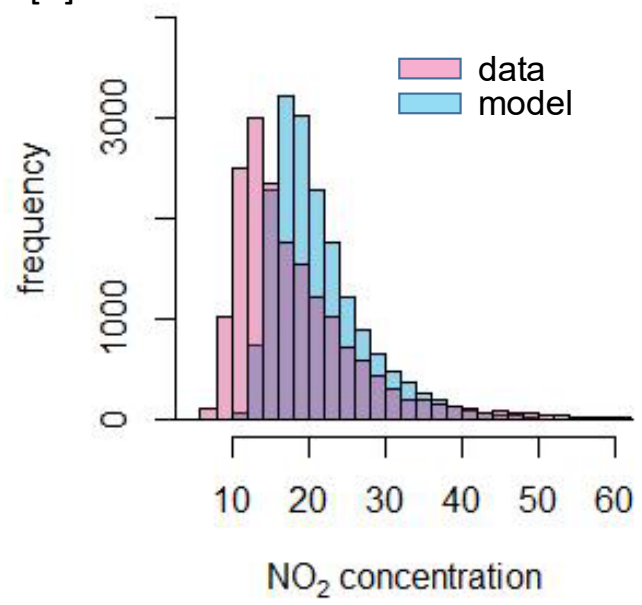

[d]

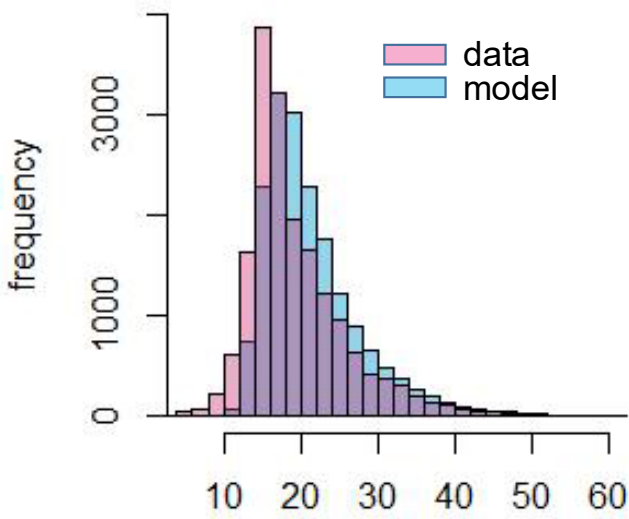

$\mathrm{NO}_{2}$ concentration

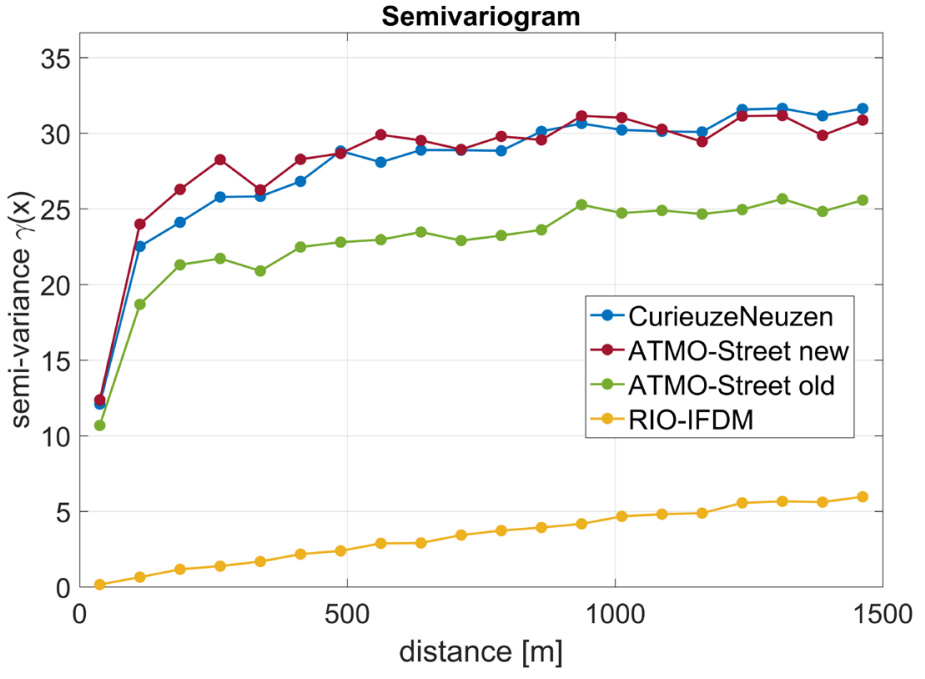

Figure 3. Ground truthing and model improvement of the ATMO-Street air quality model based on dataset from the CurieuzeNeuzen citizen science project. [a] Scatter plot with hexagonal binning and [b] histograms of measured data and simulated $\mathrm{NO}_{2}$ values with original ATMO-Street model version [c] Scatter plot with hexagonal binning and [d] histograms of measured data and simulated $\mathrm{NO}_{2}$ values after model improvement. All 
data represent averaged $\mathrm{NO}_{2}$ values over the 4-week project measurement period (May 2018). The improvement in model performance is tabulated in Extended Data Table 6. [e] The semi-variogram depicts the length scale of spatial variability in the measured $\mathrm{NO}_{2}$ (May 2018 data) and different models (RIO-IFDM: without street canyon impacts; ATMOStreet old: with street canyon impacts, before model validation; ATMO-Street new: with street canyon impacts, after model validation and model improvement). Concentrations are annual $\mathrm{NO}_{2}$ values. 


\section{Methods}

\section{Participant recruitment, communication and community building}

The objective of the communication campaign was to recruit 20.000 citizens across Flanders willing to participate in the project (as 20.000 sampling kits were pre-ordered prior to the start of the campaign). The communication campaign was co-creatively designed by the communication office of the University of Antwerp, the marketing branch of a national newspaper (De Standaard) and a professional communication agency (Bonka Circus; https://www.bonkacircus.com/en/cases/curieuzeneuzen-vlaanderen). A key contribution to the campaign's success was the decision to keep the communication positive, playful and inquisitive, emphasizing aspects of personal curiosity ("'How good is the air quality in your front garden?") as well as scientific community challenge ("Would you like be part of the largest citizen science experiment on air quality?"), while deliberately avoiding any "doom and gloom" phrases often used in air pollution communication. To further stimulate personal interest, the campaign focused on the link between air quality and daily outdoor activities that almost everyone can relate to (advertising tag lines: "How healthy is the air in which you jog/bike/play outside?"). The campaign involved mass media advertising via a range of communication channels: (1) a TV spot broadcasted during commercial breaks on national television (Extended Video 1), (2) a commercial radio ad on national radio stations, (3) a video ad broadcasted in movie theatres, (4) advertising in print media including national newspapers and magazines (Fig. 1a), and (5) Out-of-Home advertising via banners on public buses and billboards at bus stops (Fig. 1b). The objective of the mass media advertising was to achieve wide brand recognition (as many inhabitants of Flanders as possible should be aware of the project, its goals and the possibility to participate). Advertising through social media channels (Facebook, Twitter, Instagram) constituted a second important channel for recruitment, as well as subsequent community building among candidate participants. During the campaign, candidate participant registration was geographically tracked, and through sponsored posts, specific regions were targeted that were underrepresented in the registration. The project website (www.curieuzeneuzen.be) was the central information hub, providing details about the project in simple layman's terms, including the goals, scientific background and challenge, measurement procedure, and progress and results of the project. Another important recruitment channel were NGOs (cultural and environmental organizations), who supported the project and contacted members via direct mailings or newsletters to mobilize for project participation. Overall, the three-week recruitment campaign resulted in 160.688 unique visitors to the registration website, of which 52.630 registered as candidate participant (Fig. 1c-e). Registrations came from individual citizens/families, but also from schools, companies, organisations (e.g. NGOs 
or sports clubs) and local municipalities (Extended Data Table 1). The communication campaign won the Silver Effie award at the 2019 yearly awards ceremony of the national advertising sector, recognizing outstanding marketing communications in Belgium (https://www.effiebelgium.be).

\section{$\mathrm{NO}_{2}$ measurement}

The mean $\mathrm{NO}_{2}$ concentration over a 4-week sampling period (28 April 2018 to 26 May 2018) was measured in duplicate by acrylic Palmes Diffusion Tubes ${ }^{19}$ (PDT) that contain a stainless steel mesh coated with $50 \% \mathrm{v} / \mathrm{v}$ triethanolamine/acetone, a selective adsorbent for $\mathrm{NO}_{2}$ (Buro Blauw, The Netherlands). To standardize measurement conditions across participant locations, two passive $\mathrm{NO}_{2}$ samplers were strapped to the nose of a real estate panel, attached to a window pane at the side of the house facing the road (Extended Data Fig. 1b-e). These panels were standardly positioned on the first floor to avoid data loss due to theft or vandalism. A manual with detailed instructions ensured that sampler setup was similar at all locations. Sampling kits (passive samplers, panel, manual, return envelope, communication material; Extended Data Fig. 1f) were distributed to participants via a parcel delivery service. At the end of the campaign, PDTs were returned to the laboratory via the same service. Accumulated nitrite in the PDT was extracted into aqueous solution, and quantified by the Griess-Saltzman method and colorimetric absorption at $540 \mathrm{~nm}$, following the European Standard EN 16339:2013 (ref 31). Laboratory and transport blanks were included as controls. The nitrite mass was converted to the ambient $\mathrm{NO}_{2}$ concentrations (i.e. the average over the 4 week campaign) using the diffusion coefficient for $\mathrm{NO}_{2}$ in air (corrected for temperature and pressure at the sampling location, as interpolated from meteorological data across Flanders), the internal diffusion length and cross-sectional area of the PDT, and the exposure time ${ }^{32}$. The resulting $\mathrm{NO}_{2}$ data were subsequently subjected to stringent quality control and assurance, calibrated via co-joint deployment at 20 reference stations in the regional monitoring network, and converted via a statistical model to indicative annual average $\mathrm{NO}_{2}$ concentrations (as further detailed below).

\section{Supporting data}

Supporting data for each sampling location was collected through (i) questionnaires by participants, (ii) data retrieved from publicly available databases, and (iii) calculated with the ATMO-Street model ${ }^{14}$ (version 5.6.4, before model validation and adaptation, meteorological and traffic input data for the year 2016). These supporting data were used in the selection process of sample locations, in the Bayesian geospatial model, and in the air quality model simulations. During initial registration, participants provided information related to sampling location (address), and specific aspects related to air dispersal (e.g. housing type, presence of trees in the street) and local traffic (e.g. regular occurrence of traffic jams) in the street. 
Subsequently, approximate coordinates of the sampling location were calculated from the address via the Google Geocoding API, and the sampling panel position was refined by the participants on an aerial photograph of their house in a web-based mapping application (final sampling location coordinates $<5 \mathrm{~m}$ uncertainty). Final coordinates were used to extract supporting data from available GIS databases. Road type, land use type, and distance from the sampling location to the closest highway or traffic light was extracted from OpenStreetMap (https://www.openstreetmap.org). The road network and traffic data were obtained from the Roads \& Traffic Department of the Flemish Government (https://www.verkeerscentrum.be). Distance to the road edge was calculated using the GIS layer "wbn" of the topographical reference map of Flanders (https://overheid.vlaanderen.be/informatie-vlaanderen/producten-diensten/basiskaartvlaanderen-grb). The algorithm to determine whether points are located in a street canyon is part of the ATMO-Street model as described in ref 14. Population density was obtained from the Global Human Settlement - Population layer by extracting population counts in a $2000 \mathrm{~m}$ buffer around the sampling location ${ }^{33}$. As air pollutant concentrations are known to vary with height, participants were asked to record the height (relative to street level; in $\mathrm{cm}$ ) at which samplers were positioned (Extended Data Fig. 1a), in addition to the start and end time of the measurement (date:hour:min).

\section{Selection of sampling locations}

We selected $n=20.000$ sampling locations from the total pool of $n=52.630$ candidate participants (Fig. 1e), with the aim of: (1) ensuring that the distribution of measured $\mathrm{NO}_{2}$ values at the sample locations was representative for the whole population (Flanders region, Belgium), (2) obtaining the best possible dataset for groundtruthing the ATMO-Street air quality model ${ }^{14}$, and (3) maximizing the project's societal impact. To meet the latter objective, schools were given priority during selection (as classroom participation stimulates STEM education), and also collective measurements performed by organisations, companies and governmental bodies (as they are carried out by a team of persons, thus maximizing societal impact). The remaining sampling locations were allocated to the "individuals /families" category. In this category, locations were prioritized that strictly fulfilled the criteria of the standardized measurement setup (positioning on the first floor facing the street). Furthermore, a stepwise procedure was developed that ensured a good geographical spreading of sampling locations (thus sampling across areas with different background concentrations), as well as a suitable coverage of all different "pollution environments" within a given area (thus sampling across locations with different emission and dispersion characteristics). In a first step, the mean annual $\mathrm{NO}_{2}$ concentration (denoted C) was estimated at each $n=52.630$ candidate locations with ATMO-Street version 5.6.4 
(see below). The model decomposes the local concentration as $C=C_{B G}+C_{L T}$, where $C_{B G}$ represents the background concentration and $C_{L T}$ the contribution from line emissions due to traffic. In a second step, sample locations were divided into three categories, based on information about air dispersal in the local street geometry (open site or street canyon) and the impact of traffic line emissions ("background" $=\mathrm{C}_{\mathrm{LT}} / \mathrm{C} \leq 0.25$, "traffic-impacted open" = $\mathrm{C}_{\mathrm{LT}} / \mathrm{C}>0.25$ and open street geometry, and "traffic-impacted street canyon" $=\mathrm{C}_{\mathrm{LT}} / \mathrm{C}>0.25$ and street canyon geometry). For each category, locations were binned according to their model-derived $\mathrm{NO}_{2}$ values (P20, P40, P60, P80, P100 of the histogram). In a final step, suitable quota $X_{k}$ (with $\Sigma X_{k}=20.000$ ) were attributed to each bin, and sampling locations were sequentially selected ensuring maximal spatial separation ("select $X_{k}$ locations from the total of $Y_{k}$ locations in the $k^{\text {th }}$ bin ensuring a maximal geographical spread given the $X_{i}$ with $\mathrm{i}=1, \mathrm{k}-1$ locations already selected). Maximal geographical spread was determined based on the nearest neighbour distance $d$ measured "as the crow flies". A higher density of measurement locations was allowed in urbanized areas $(d \sim 100 \mathrm{~m})$ compared to rural areas (d 500m) due to steeper concentration gradients.

\section{Data quality control and assurance}

From the 20.000 sampling locations, $95.8 \%(n=19.155)$ generated a valid measurement, implying that passive samplers were returned, all necessary supporting data were available, and chemical analysis was successful for at least one passive sampler (Extended Data Table 2). During an initial round of data profiling, we discovered 12 sampling locations that had anomalously low $\mathrm{NO}_{2}$ values compared to the regional background, likely because diffusion tubes had not been opened. From the remaining dataset, 1051 data points were discarded for further data analysis, because there was a problem with at least one of the passive samplers (sent back without end cap, damaged diffusion tube, tube contained water inside, code identification of the tube was not possible, measurement below Limit Of Detection), or because the measurement duration was shorter than 24 days ( $<85 \%$ of the full 28-day measurement period). To further improve the data quality, we compared the duplicate measurements at each location and removed outliers based on a quantile regression ${ }^{34}$. To this end, duplicate measurements were log2 transformed, and the difference between duplicates was regressed versus the duplicate mean (Extended Data Fig. 2) The $1^{\text {st }}$ and $3^{\text {rd }}$ quantile (Q1 and Q3) and interquartile range (IQR) of the duplicate difference were determined. Data points were considered outliers when the duplicate difference was either below Q1-3*IQR or above Q3+3*IQR (red markers in Extended Data Fig. 2). We opted for a non-parametric quantile regression, as we had no preconceived notion of how the variation on the measurement result would depend on the concentration. 
In total, 260 samples were qualified as outliers, thus resulting in a final set of $n=17.886$ data points used for statistical and model analysis (Extended Data Table 2).

\section{Sampler calibration}

Previous studies have shown that passive samplers require field evaluation at reference stations to calibrate their uptake rates to environmental conditions ${ }^{35}$. A calibration procedure was therefore applied to the $\mathrm{NO}_{2}$ sampler data (mean concentration over 4 week period) to reduce any potential bias in the passive sampler approach. To this end, the sampling set-up was co-located at $\mathrm{N}_{R}=20$ reference stations within the monitoring network of the Flanders Environment Agency (Vlaamse Milieumaatschappij). These reference stations are geographically spread across the study domain and target a diverse set of emission environments (thus covering a suitable range of low to high $\mathrm{NO}_{2}$ concentrations). The colocation used the same sampler deployment procedure (i.e., Palmes diffusion tubes strapped in the nose of a real estate panel) and took place over exactly the same time period as the project measurements. A panel containing 4 replicate passive samplers was mounted as close as possible to the inlet of the chemiluminescence gas analysers on all reference monitoring stations. The reference data $X_{i}\left(i=1 . . N_{R}\right)$ represent the mean $\mathrm{NO}_{2}$ concentration over the 4 week campaign period as calculated from 30 minute averaged $\mathrm{NO}_{2}$ concentrations as measured by chemiluminescence. The sampler data $Y_{i}\left(i=1 . . N_{R}\right)$ represent the mean $\mathrm{NO}_{2}$ concentration as calculated from the 4 passive samplers that were co-located. Three separate statistical models were applied to relate the sampler data $Y_{i}$ to the reference data $\mathrm{X}_{\mathrm{i}}$ : orthogonal regression, constant off-set and ratio multiplication.

$$
\begin{gathered}
Y_{i}=a * X_{i}+b \\
Y_{i}=X_{i}+c \\
Y_{i}=r * X_{i}
\end{gathered}
$$

In the orthogonal regression model described by equation (1), the slope a and intercept $b$ were calculated using Deming regression using the 'mcreg' function in the R package ' $m c r^{\prime 36}$, assuming equal uncertainties for $\mathrm{Xi}$ and $\mathrm{Yi}$. The parameter $\mathrm{c}$ in the constant off-set model was determined as the mean of all individual offsets

$$
c=\frac{1}{n} \sum_{i=0}^{n}\left(Y_{i}-X_{i}\right)
$$


In the ratio multiplication model, the parameter $r$ was determined as the mean of the individual ratios for all

stations

$$
r=\frac{1}{n} \sum_{i=0}^{n}\left(\frac{Y_{i}}{X_{i}}\right)
$$

Extended Data Fig. 3 shows the results of the calibration procedure, showing a linear trend over the concentration range from 15 to $50 \mu \mathrm{g} / \mathrm{m}^{3}$. The slope of the orthogonal regression model approximates 1 , and as a result, the orthogonal regression and intercept models provide nearly similar regression lines. Sampler data are systematically smaller than reference data, indicating a negative bias. Previously, PDTs have often been observed to overestimate concentrations measured by automatic analysers during co-location studies ${ }^{37}$, which is the opposite as found here. $\mathrm{NO}_{2}$ concentrations measured by unsheltered Palmes samplers show a positive dependence upon wind-speed, indicating that increased turbulence shortens the effective diffusion path length ${ }^{38}$. Chamber and wind-tunnel studies have also reported positive associations between wind-speed on the one hand and sampler uptake rates for open tube samplers on the other hand ${ }^{39-40}$. We believe that the wind sheltering effect offered by attachment of the Palmes samplers to the real estate panel has prevented the typical sampler overestimation. The lower sampler concentrations are likely due to a small loss of absorbed $\mathrm{NO}_{2}$ from the TEA absorbent $\left(\sim 9 \%\right.$ at $\left.40 \mu \mathrm{g} / \mathrm{m}^{3}\right)$ over the 4 week sampling period, as has been reported previously ${ }^{41-42}$.

Compared to other studies ${ }^{37}$, we obtained a high correlation between passive sampler and reference measurements, thus providing a good basis for calibration. We used the jackknife or leave-one-out (LOO) method to estimate the model uncertainty (root mean square error), implementing the 'jackknife' function from the R package 'bootstrap' 43 . We performed the analysis both for 4 samplers (as in the co-location deployment) as well as 2 samplers (mimicking the situation during the actual citizen measurement). The intercept model showed the lowest model uncertainty (Extended Data Table 5), and so we implemented the resulting calibration equation:

$$
\mathrm{Yi}=\mathrm{Xi}+3.6 \mu \mathrm{g} / \mathrm{m}^{3}
$$

In this, $\mathrm{Y}_{\mathrm{i}}$ represents the calibrated $\mathrm{NO}_{2}$ value and $\mathrm{X}_{\mathrm{i}}$ the original measured $\mathrm{NO}_{2}$ value (mean of the two replicate passive samplers). The 95\% confidence interval on the correction term was $3.2-4.0 \mu \mathrm{g} / \mathrm{m}^{3}$. Assuming the errors are random and uncorrelated, we can combine the standard deviations of the passive sampler measurement $\left(1.7 \mu \mathrm{g} / \mathrm{m}^{3}\right)$ and calibration $(2.2$ $\mu \mathrm{g} / \mathrm{m}^{3}$ ), thus resulting in a deviation of $3.9 \mu \mathrm{g} / \mathrm{m}^{3}$, or equally, a relative uncertainty of $10 \%$ at the WHO-guideline value of $40 \mu \mathrm{g} / \mathrm{m}^{3}$.

\section{Normalisation to annual $\mathrm{NO}_{2}$ values}


The monitoring period for passive $\mathrm{NO}_{2}$ samplers is restricted (3-4 weeks in an urban context) to avoid that passive samplers become saturated. Therefore, the measurement period was set to 4 weeks, and so, our calibrated $\mathrm{NO}_{2}$ values essentially represent monthly averaged concentrations over May 2018. Compliance checking with guideline values of the World Health Organisation (WHO) or limit values of the EU is however based on yearly-averaged $\mathrm{NO}_{2}$ values (threshold value of $40 \mu \mathrm{g} \mathrm{m}^{-3}$ ) that necessitate a regularly distributed measurement effort throughout the year. Data collected in the CurieuzeNeuzen project do not meet this criterion.

To still enable compliance checking, we implemented a recently developed normalisation procedure that reliably extrapolates the time-limited results of $\mathrm{NO}_{2}$ passive samplers from multi-week averages to yearly averaged values ${ }^{22}$. The central premise of this procedure is that air quality shows spatial synchrony: different sampling locations will show similar longer-term trends in $\mathrm{NO}_{2}$ concentrations when these concentrations are averaged over multiple weeks. This implies that there is a high correlation between multi-weekaveraged $\mathrm{NO}_{2}$ values and yearly-averaged $\mathrm{NO}_{2}$ values for sampling stations within a wider region. Analysis reveals that $\mathrm{NO}_{2}$ concentrations across Flanders indeed show suitable spatial synchrony 22 .

To build the extrapolation model, we used $\mathrm{NO}_{2}$ data as measured by chemiluminescence from $\mathrm{N}_{\mathrm{R}}=52$ reference stations within the monitoring network of the Flanders Environment Agency. The values $\mathrm{X}_{\mathrm{i}}\left(\mathrm{i}=1\right.$.. $\left.\mathrm{N}_{\mathrm{R}}\right)$ represent the mean $\mathrm{NO}_{2}$ concentration over the 4 week period (May 2018) as calculated from 30 minute averaged $\mathrm{NO}_{2}$ concentrations determined by chemiluminescence. The values $Y_{i}\left(i=1 . . N_{R}\right)$ represent the annual mean $\mathrm{NO}_{2}$ concentration as calculated from the 30 minute averaged $\mathrm{NO}_{2}$ calculated over a one-year period from June 2017 to May 2018. Three separate statistical models were applied to relate the sampler data $Y_{i}$ to the reference data $X_{i}$ : orthogonal regression, constant off-set and ratio multiplication - as specified by equations (1) to (5). The model uncertainty (root mean square error) was calculated by the jackknife or leave-one-out (LOO) method as described above. Extended Data Fig. 4 shows the results of the extrapolation procedure. The data show a linear trend over the concentration range from 15 to $55 \mu \mathrm{g} / \mathrm{m}^{3}$. The trend lines predicted by the models are similar and match closely the $1: 1$ line. The intercept $\left(3.4 \mu \mathrm{g} / \mathrm{m}^{3}\right)$ and orthogonal regression $\left(3.4 \mu \mathrm{g} / \mathrm{m}^{3}\right)$ models show a lower model uncertainty $u_{m}$ than the ratio model $\left(3.7 \mu \mathrm{g} / \mathrm{m}^{3}\right)$. To arrive at annual averaged $\mathrm{NO}_{2}$ concentrations, we implemented the intercept model using the equation:

$$
\mathrm{Yi}=\mathrm{Xi}+1.5 \mu \mathrm{g} / \mathrm{m}^{3}
$$


In this, $X_{i}$ represents the calibrated monthly $\mathrm{NO}_{2}$ value and $Y_{i}$ the indicative annual mean $\mathrm{NO}_{2}$ value. The $95 \%$ confidence interval on the correction term was $0.5-2.5 \mu \mathrm{g} / \mathrm{m}^{3}$. The expanded relative model uncertainty $\left(U m=k^{*} u_{m} / C_{\text {ref }}\right.$ with $u_{m}=3.4 \mu g / m^{3}$, cover factor $k=2$ and $\mathrm{C}_{\text {ref }}=\mathrm{WHO}$-guideline value of $40 \mu \mathrm{g} / \mathrm{m}^{3}$ ) amounts to $17 \%$. While the European Air Quality Directive does not explicitly endorse any data normalisation procedure for compliance checking, the annual $\mathrm{NO}_{2}$ data obtained from our extrapolation model satisfy the requirements of the Directive (expanded relative model uncertainty $<30 \%$ with respect to the data), thus attesting to the data quality that citizen-based approach can achieve.

\section{Societal impact analysis.}

To assess the societal impact of the project, three different groups $(n=20.000$ participants, $n=32.630$ non-selected candidates, and a reference group of citizens not connected to the project) were surveyed at three different points in time (longitudinal survey). Each survey contained a mix of closed questions, multiple choice and open questions, varying between 25 to 38 main questions per survey. A first survey was conducted during the period of the actual air quality measurements (May-June 2018), a second survey took place after the announcement of the measurement results (November-December 2018), and a third survey occurred more than one year after the start of the project (July 2019). The response rate to the online questionnaires was high, illustrating the high level of motivation: $33 \%$ of all participants $(n=5.369)$ and $13 \%$ of non-selected candidates $(n=4.287)$ took part in all survey rounds organized for their group. The reference group $(n=1.000)$ consisted of a representative sample of the Flemish population for the parameters of age, gender, level of education and provincial region. The composition of the respondents was verified across the three survey rounds. Respondents were anonymous but linked through a unique identifier, and in this way, individual participation was traced in the surveys. The survey analysis was complemented further by interviews with key stakeholders and a desktop review of project coverage in national and official documents.

The CurieuzeNeuzen project shows broad socio-demographic diversity, attracting far more female participants (48\%) and more persons with a limited educational background $(16 \%$ has no diploma of higher education) compared to other citizen-science projects, which tend to have a strong over-representation of men, highly educated people, and technicallyoriented educational backgrounds ${ }^{44}$. Similar to other projects, there remains a strong underrepresentation of persons with a migration background.

With its large-scale participation and 20.000 measurement locations, the project established an extensive network for creating direct outreach. We estimate that $3 \%$ of the population of Flanders (6.5 million inhabitants) was in direct contact with the project (i.e., living in a family, 
at school, working in a company team where an experiment was conducted). The outreach of the project was further increased as participants were stimulated to act as project ambassadors. They distributed $\sim 140,000$ flyers in their local neighbourhood, explaining the project, and talked to an estimated 430,000 citizens (friends, family, neighbours, colleagues at work) about the project ( $7 \%$ of the population). Because of its large size, the project received a lot of attention in mainstream media, which further amplified its reach. In May $2018,77 \%$ of the reference panel indicated that they knew the project, and $49 \%$ was able to explain what the project was about, thus attesting to wide brand recognition. A year later, CurieuzeNeuzen was still known by a large section of society: $71 \%$ knew the project and $45 \%$ could indicate what it was about.

\section{Bayesian geospatial modelling}

A Bayesian Hierarchical Spatial Model was developed, where the response variable $Y$, representing the log-transformed average of the duplicated $\mathrm{NO}_{2}$ measurements at the sampling locations $\mathrm{s}$, was regressed against a set of the spatially varying covariates $\mathrm{X}$. Following previous studies ${ }^{45,46}$, the following spatial regression model is adopted:

$\boldsymbol{Y}_{s}=\beta_{0}+X_{s} \boldsymbol{\beta}+u_{s}+\varepsilon_{s}, \quad s=1, \ldots, S$

where $\beta_{0}$ is the intercept term, $\beta$ the vector of regression coefficients, $S$ the total number of individual sampling locations, $u_{s}$ the spatial random effect and $\varepsilon_{s}$ the residual gaussian noise, assumed to be independent and identically distributed $\left(\mathcal{N}\left(0, \sigma_{s}^{2}\right)\right)$. The spatial correlated random effect was assumed to originate from a multivariate normal distribution $\left(\mathcal{N}\left(0_{s}, \sigma_{u}^{2} \Sigma_{u}\right)\right.$ with mean 0 and a covariance defined by the Matérn correlation function with the smoothing parameter set to 1 (as $\mathrm{in}^{46,47}$ ). Given the size of the covariance matrix ( $\boldsymbol{\Sigma}: \mathbf{S} \mathrm{x}$ S), computational efficiency was obtained by making use of the Integrated Nested Laplace Approximation (INLA) ${ }^{48}$ and the stochastic partial differential equation (SPDE) approach ${ }^{49}$ as adopted in R-INLA ${ }^{47}$. This method is only briefly described here; the underlying theory is provided elsewhere ${ }^{50}$. In order to solve the SPDE and estimate the parameters of the Matern correlation function, a dense triangular network was placed over the sampling area (Extended Data Fig. 9a), following the methodology employed in ref 47.

The set of covariates $X$ was chosen to represent factors driving local wind-driven dispersal of pollutants, local or regional emission sources of $\mathrm{NO}_{2}$, and wider background variations (Extended Data Table 3). Street-level ventilation was accounted for by whether the street functions as a street canyon according to the ATMO-Street model ${ }^{14}$, the geometry of roadside buildings [detached (reference), semi-detached and terraced] and the presence of trees within the street [no trees (reference), sparse tree coverage and high tree coverage]. 
Street-level emissions were either linked to the mean traffic volume, using street type as a proxy for traffic intensity [residential (reference), primary, secondary, tertiary, living street, pedestrian and service roads], or resulting from decreased traffic fluidity, as modelled by the distance to traffic lights [ $<50 \mathrm{~m}$ (reference), 50-100,100-250 m, >250m] and reports of frequent traffic jams by participants [no (reference), yes]. The distance of the sampling location to street-level emissions was accounted for by sampling height [ground, first (reference) and second floor] and distance from the street edge [0-2 m (reference), 2-5 m, 5$10 \mathrm{~m}$, and $>10 \mathrm{~m}]$. Variables describing emissions beyond the street level, were distance to motorway (log10 transformed), scaled population density within a $2000 \mathrm{~m}$ radius, and land use [residential (reference), commercial, farming, greenspace \& industrial]. Larger-scale background variations in $\mathrm{NO}_{2}$ levels were modelled by including Easterness and Northerness. Continuous covariates were standardised prior to inclusion and the model was restricted to one-way interactions. Default priors provided by R-INLA were used, which consist of a zero-mean normal distribution with a precision of 0.001 for the fixed effect regression coefficients and the error term, and sets a sensible prior median and precision for the spatial correlation range.

Model performance was assessed by calculation of the Deviance Information Criterion (DIC) and the Watanabe-Akaike Information Criterion (AIC) for different models. Models with and without covariates or spatial structure were evaluated, as well as lognormal and gamma distributions for the residual errors (Extended Data Table 6). A model including covariates, a spatial random field and assuming residuals to arise from a lognormal distribution performed best (DIC = 84.609; WAIC = 84.555), and was hence selected as the final inferential model. Backward stepwise covariate selection was performed and the selected model retained all initial covariates.

The resulting inferential model is presented in Extended Data Table 3 and Extended Data Fig. 5 , and is based on $\mathrm{N}=17.824$ sampling locations that had all required supporting data available for the predictors. The spatial random effect accounted for $30.5 \%$ of the total variation (Extended Data Fig. 8b). Notably both the port of Antwerp as well as the harbour of Zeebrugge are positively correlated with $\mathrm{NO}_{2}$ levels, suggesting that $\mathrm{NO}_{2}$ emissions from shipping are likely a missing covariate. The statistical model demonstrated considerable predictive ability $\left(R^{2}=0.77\right.$ ), validated through 5 -fold cross validation on a $20 \%$ left-out test. The performance of the predictive geospatial model is higher compared to ATMO-Street model (Extended Data Table 4), but comparable to Bayesian spatial models for particulate matter $^{46}$.

\section{Atmospheric dispersion modelling}


The ATMO-Street model chain ${ }^{14}$ consists of three modules: (i) the land-use based interpolation model RIO determining background concentrations ${ }^{51}$, (ii) a bi-gaussian plume dispersion model IFDM accounting for local emissions from traffic and other sources ${ }^{14}$, and (iii) a street canyon module (OSPM) that calculates the in-street increment resulting from street canyon effects ${ }^{52}$. The regional background model RIO was set up using the official $\mathrm{NO}_{2}$ reference measurements of the telemetric system of the EPA Flanders (VMM), and the Copernicus Corine Land Cover 2018 (Version 2020_20u1) as land-use input. The Gaussian dispersion model IFDM and street canyon model OSPM used the official road traffic emissions of the Flemish Government, combined with official point source emissions for industry and line source emissions for shipping. Meteorological data (spatial resolution $1 \mathrm{~km}$ x $1 \mathrm{~km}$ ) were obtained as data-assimilated hourly validate ECMWF data (data for 2016 and 2018). Building data were retrieved from the official building dataset for Flanders (https://overheid.vlaanderen.be/informatie-vlaanderen). Different types of $\mathrm{NO}_{2}$ simulations were performed with the ATMO-Street model: (1) preliminary $\mathrm{NO}_{2}$ simulation used in the selection for sampling location selection (version 5.6.4, input: meteorological and traffic data for the year 2016; output: mean annual $\mathrm{NO}_{2}$ for 2016) (2) simulation of mean $\mathrm{NO}_{2}$ at all sampling locations with existing model (ATMO-Street version 5.6.4, input: meteorological and traffic data for 2018; output: mean $\mathrm{NO}_{2}$ over the same 4 week period as the passive sampler measurements, 28 April 2018 to 26 May 2018), (3) simulation of mean $\mathrm{NO}_{2}$ at all sampling locations after model improvement (version 6.2.0, input: meteorological and traffic data for 2018; output: mean $\mathrm{NO}_{2}$ over the 4-week campaign period), (4) simulation of timevarying $\mathrm{NO}_{2}$ for dynamic exposure calculations (version 6.2.0, input: meteorological and traffic data for 2018; output: annual averaged $\mathrm{NO}_{2}$ concentrations at different hours of the day).

\section{Verification of representativeness}

The question of representativeness can be posed in following way: if one would conduct the same $\mathrm{NO}_{2}$ passive sampler measurements at all the houses in Flanders, would one obtain the same frequency distribution for the $\mathrm{NO}_{2}$ concentration? The problem is that the frequency distribution of $\mathrm{NO}_{2}$ concentrations at all houses in Flanders is unknown, and cannot be compared to the frequency distribution of $\mathrm{NO}_{2}$ data as obtained in the CurieuzeNeuzen project. Still, we can assess the representativeness through atmospheric dispersion modelling, and the rationale of this procedure is summarized in Extended Data Fig. 6. First, we estimated the $\mathrm{NO}_{2}$ concentration at the main house entrance for each participant with valid data in the CurieuzeNeuzen project $\left(\mathrm{N}_{\mathrm{CN}}=17.886\right)$ using the ATMOStreet air quality model and determined the associated frequency distribution. Subsequently, we estimated the $\mathrm{NO}_{2}$ concentration at the main house entrance of all residential locations 
(facing the street) for all inhabitants in Flanders $\left(\mathrm{N}_{\mathrm{FL}}=6.093 .814\right)$ using the ATMO-Street model and determined the associated frequency distribution. If both frequency distributions are similar, then the CurieuzeNeuzen sampling locations are likely to form a representative subsample of the $\mathrm{NO}_{2}$ air quality at the facade locations of all inhabitants in Flanders. We made a similar comparison for schools, comparing the $\mathrm{NO}_{2}$ distribution of the $\mathrm{S}_{\mathrm{NS}}=651$ schools in the de CurieuzeNeuzen dataset to the $\mathrm{NO}_{2}$ distribution of all $\mathrm{S}_{\mathrm{FL}}=11.799$ school locations across Flanders. The coordinates of the $\mathrm{N}_{\mathrm{CN}}=17.886$ participant locations and $\mathrm{S}_{\mathrm{NS}}$ $=651$ school locations were retrieved from the $\mathrm{CN}$ database. The coordinates of the inhabitant and school locations across Flanders were retrieved from publicly available database (http://www.geopunt.be). Model simulations were carried out with the ATMO-Street model over the 4 week measurement period of the project (28 April 2018 to 26 May 2018). Compared to the model-data comparison, the simulation procedure was adapted at one specific point, i.e., we could only retrieve the position of the main house entrance, which is not necessarily located at the street-facing side of the house (while all CurieuzeNeuzen sampling locations occurred at the front of the house). To account for this, we adapted the OSPM street canyon module within ATMO-Street, so that both the centre of each house and the front of each house belonged to the same street canyon. Via this modification, the simulation of $\mathrm{NO}_{2}$ concentrations for CurieuzeNeuzen participants and inhabitants of Flanders occur in the same way, thus providing internally consistent frequency distributions that enable the verification of representativeness.

\section{Dynamic exposure modelling}

Dynamic exposure was calculated by combining ATMO-Street simulations with time-location patterns from CurieuzeNeuzen participants obtained by self-reporting through a questionnaire. 5.020 respondents provided valid data on work location (for workers) or another out-of-home location (for non-workers), travel to this location and time-use. We assumed that a person visits only one out-of-home location per day. Dynamic exposure was modelled for an average weekday as the time-weighted exposure at home, at an out-ofhome location, and while commuting. The estimated annual $\mathrm{NO}_{2}$ concentration as derived from the citizen-based measurements served as the $\mathrm{NO}_{2}$ concentration at home. Time spent at home was the time that was not spent out-of-home or traveling. Out-of-home addresses were self-reported, and geocoded with the Google Geocoding API. The coordinates were combined with the ATMO-Street model simulations to determine the $\mathrm{NO}_{2}$ concentration at the out-of-home location. The ATMO-Street model only considered daytime hours ( 5 am to $11 \mathrm{pm}$ ) as we hypothesize that out-of-home activities were happening mostly during the day. Time spent at the out-of-home location was reported by the participants. The method of transport to reach the out-of-home destination and associated travel time were also self- 
reported. The route was simulated with the Google Directions API, using the reported main transport mode: walking, biking, public transport (bus, tram, train), or car. The route was generated for a Tuesday in May 2018, leaving at 8 am, and for a date two weeks in the future (most trips were commutes to work). The routing engine accounts for a representative traffic situation, including rerouting or longer travel times due to traffic jams. The polyline was then transformed into equidistant points along the route (50 meters interdistance), and was combined with the ATMO-Street model simulation to obtain $\mathrm{NO}_{2}$ concentrations at a particular point in time and space during the daytime. Travel time and distance predicted by Google was used in subsequent analyses (not the self-reported travel time).

\section{Software and code}

All operations regarding data quality assurance, calibration, normalisation, dynamic exposure estimation and statistical analysis were performed in R. GIS operations to obtain spatial supporting data were performed in QGIS and R. R scripts for calibration, normalisation, and statistical analysis are available upon request. 


\section{Methods references}

31. Comite Europeen de Normalisation, Ambient Air - Method for the Determination of the Concentration of Nitrogen Dioxide by Diffusive Sampling, EN 16339:2013

32. Targa, J. \& Loader, A. Diffusion Tubes for Ambient $\mathrm{NO}_{2}$ Monitoring: a Practical Guide (No. AEA/ENV/R/2504-Issue 1a). AEA Energy and Environment (2008).

33. Freire, MacManus, Pesaresi, Doxsey-Whitfield, \& Mills, 2016

34. Cho H.J., Kim Y., Jung H.J., Lee S.-W. \& Lee J.W. OutlierD: an R package for Outlier Detection Using Quantile Regression on Mass Spectrometry Data (2008).

35. Heal, M.R., Laxen, D.P.H. \& Marner, B.B. Biases in the Measurement of Ambient Nitrogen Dioxide $\left(\mathrm{NO}_{2}\right)$ by Palmes Passive Diffusion Tube: A Review of Current Understanding. Atmosphere, 10, 357-385 (2019).

36. Manuilova, E., Schuetzenmeister, A. \& Model, F. Mcr: an R package for Method Comparison Regression, 2014.

37. Cape, J.N. The use of passive diffusion tubes for measuring concentrations of nitrogen dioxide in air. Crit. Rev. Anal. Chem. 39, 289-310 (2009).

38. Masey, N. et al. Influence of wind-speed on short-duration $\mathrm{NO}_{2}$ measurements using Palmes and Ogawa passive diffusion samplers. Atmos. Environ., 160, 70-76 (2017).

39. Buzica, D. et al. Modelling of the uptake rate of the nitrogen dioxide Palmes diffusive sampler based on the effect of environmental factors. J. Environ. Monit. 7, 169-174 (2005).

40. Martin, N.A. et al. Measurement of nitrogen dioxide diffusive sampling rates for Palmes diffusion tubes using a controlled atmosphere test facility (CATFAC). Atmos. Environ. 94, 529-537 (2014).

41. Heal, M.R., Kirby, C. \& Cape, J.N. Systematic biases in measurement of urban nitrogen dioxide using passive diffusion samplers. Environ. Monit. Assess. 62, 39-54 (2000).

42. Kirby, C. et al. Influence of environmental parameters on the accuracy of nitrogen dioxide passive diffusion tubes for ambient measurement. J. Environ. Monit. 3, 150158 (2001).

43. Tibshirani, R. \& Leisch, F. Bootstrap: An R package with functions for the Book "An Introduction to the Bootstrap" (2019). 
44. Dibner K.A., \& Pandya R. Learning Through Citizen Science: Enhancing Opportunities by Design. National Academies Press (2018)

45. Cameletti, M. et al.. Spatio-temporal modeling of particulate matter concentration through the SPDE approach. AStA Adv. Stat. Anal. 97, 109-131 (2013).

46. Beloconi, A., et al. Bayesian geostatistical modelling of PM10 and PM2.5 surface level concentrations in Europe using high-resolution satellite-derived products. Environ. Int. 121, 57-70 (2018)

47. Bakka, H., et al. Spatial modeling with R - INLA: A review. Comp. Stat., 10, e1443 (2018).

48. Rue, H., Martino, S. \& Chopin, N.. Approximate bayesian inference for latent gaussian models by using integrated nested laplace approximations. J. R. Stat. Soc.: Ser. B 2. 71, 1-35 (2009).

49. Lindgren, F., Rue, H. \& Lindström, J. An explicit link between gaussian fields and gaussian markov random fields: the stochastic partial differential equation approach. J. R. Stat. Soc. Ser. B Stat. Methodol. 73, 423-498 (2011).

50. Blangiardo, M. \& Cameletti, M.. Spatial and Spatio-temporal Bayesian Models with RINLA. John Wiley \& Sons (2015)

51. Janssen, S., et al. Spatial interpolation of air pollution measurements using CORINE land cover data. Atmos. Environ. 42, 4884-4903 (2008).

52. Berkowicz, R. OSPM - A parameterised street pollution model. Environmental Monitoring and Assessment 65, 323-331 (2000). 


\section{Acknowledgements}

We thank the volunteers of the CurieuzeNeuzen team and the Ringland citizen movement, who helped developing the CurieuzeNeuzen pilot project in Antwerp 2016, and the City of Antwerp for financial support. In the subsequent 2018 CurieuzeNeuzen Vlaanderen campaign, we received support with logistics and communication of many co-workers at UAntwerpen, De Standaard, and VMM, as well as scientific and non-scientific collaborators at VMM, IRCEL, VITO, HIVA KU Leuven, Bonka Circus and Kariboo. Yet, foremost, we thank all participants in the CurieuzeNeuzen Antwerpen and CurieuzeNeuzen Vlaanderen campaigns, for their enthusiastic and accurate data collection.

\section{Author contributions}

FJRM and HHuyse developed the original concept of large-scale citizen-based air quality monitoring underlying the CurieuzenNeuzen project, in co-creation with 12 volunteers. SDC, JV, JVdB and FJRM designed and performed data calibration and upscaling procedures. VS, SDC and FJRM developed the spatial regression model. WL, HHooyberghs and SDC performed ATMO-Street modelling. HHuyse conducted societal impact analysis. ED performed dynamic exposure modelling. FJRM wrote the manuscript with input from all coauthors.

Competing interest declaration: The authors declare that they have no conflict of interest.

Additional information: Correspondence and requests for materials should be addressed to FJRM (Filip.Meysman@uantwerpen.be).

\section{Supplementary information}

Supplementary Video 


\section{Extended data tables}

\begin{tabular}{l|cc|cc|}
\hline Type participant & Candidates & Percentage & Selected & Percentage \\
\hline Individuals / families & 49.778 & $94.6 \%$ & 18.046 & $90.2 \%$ \\
Schools & 967 & $1.8 \%$ & 784 & $3.9 \%$ \\
Companies & 920 & $1.7 \%$ & 161 & $0.8 \%$ \\
Organisations & 965 & $1.8 \%$ & 514 & $2.6 \%$ \\
Local municipalities & 597 & $1.1 \%$ & 495 & $2.5 \%$ \\
\hline Total & $\mathbf{5 2 . 6 3 0}$ & $\mathbf{1 0 0} \%$ & $\mathbf{2 0 . 0 0 0}$ & $\mathbf{1 0 0 \%}$ \\
\hline
\end{tabular}

Extended Data Table 1. Overview of candidate participants and selected participants for the CurieuzeNeuzen citizen science project. 


\begin{tabular}{llllll}
\hline Reason for data removal & Amount & & \multicolumn{2}{l}{ Remaining } & \\
\hline Initial measurement locations & & & 20.000 & $100 \%$ \\
\hline Samplers not returned by participants & -159 & $0.8 \%$ & 19.841 & $99.2 \%$ \\
Supporting data missing & -358 & $1.8 \%$ & 19.483 & $97,4 \%$ \\
Samplers lost during transport & -178 & $0.9 \%$ & 19.305 & $96,5 \%$ \\
Problem during chemical analysis & -138 & $0.7 \%$ & 19.167 & $95,8 \%$ \\
Unrealistically high or low values & -12 & $0.1 \%$ & 19.155 & $95,8 \%$ \\
\hline Locations with a valid measurement & & & 19.155 & $95,8 \%$ \\
\hline Only valid data for 1 passive sampler & -904 & $4.5 \%$ & 18.251 & $91,3 \%$ \\
\hline Too short measurement period (<24 days) & -147 & $0.7 \%$ & 18.104 & $90,5 \%$ \\
\hline Too large deviation between replicates & -261 & $1.3 \%$ & 17.843 & $89.2 \%$ \\
\hline Extra data at reference stations & +43 & $0.2 \%$ & 17.886 & $89.4 \%$ \\
\hline Data points retained after QC/QA & & & 17.886 & $89.4 \%$ \\
\hline
\end{tabular}

Extended Data Table 2. Overview of data control and quality assurance procedure in the CurieuzeNeuzen citizen science project. 


\begin{tabular}{|c|c|c|c|}
\hline Covariate & Mean & $2.5 \%$ C.I. & 97.5\% C.I. \\
\hline INTERCEPT & 3.214 & 3.192 & 3.237 \\
\hline EASTERNESS & -0.034 & -0.043 & -0.025 \\
\hline NORTHERNESS & 0.046 & 0.037 & 0.056 \\
\hline POPULATION DENSITY & 0.069 & 0.061 & 0.077 \\
\hline DISTANCE TO MOTORWAY & -0.167 & -0.177 & -0.156 \\
\hline \multicolumn{4}{|l|}{ LAND USE } \\
\hline Residential & Reference & & \\
\hline $\begin{array}{r}\text { Commercial } \\
\text { Farming }\end{array}$ & $\begin{array}{r}0.039 \\
-0.021\end{array}$ & $\begin{array}{l}0.002 \\
-0.031\end{array}$ & $\begin{array}{l}0.0 / 6 \\
-0.011\end{array}$ \\
\hline Greenspace & -0.032 & -0.044 & -0.020 \\
\hline Industrial & 0.047 & 0.024 & 0.069 \\
\hline \multicolumn{4}{|l|}{ STREET TYPE } \\
\hline Residential & Reference & & \\
\hline Primary & 0.185 & 0.175 & 0.195 \\
\hline Secondary & 0.137 & 0.129 & 0.145 \\
\hline Tertiary & 0.048 & 0.044 & 0.053 \\
\hline Living Street & -0.035 & -0.056 & -0.014 \\
\hline Pedestrian & -0.061 & -0.097 & -0.025 \\
\hline Service & 0.020 & 0.008 & 0.032 \\
\hline \multicolumn{4}{|l|}{ DISTANCE TO TRAFFIC LIGHT } \\
\hline $0-50 \mathrm{~m}$ & Reference & & \\
\hline $50-100 m$ & -0.088 & -0.109 & -0.068 \\
\hline $100-250 m$ & -0.141 & -0.158 & -0.123 \\
\hline$>250 \mathrm{~m}$ & -0.176 & -0.194 & -0.159 \\
\hline \multicolumn{4}{|l|}{ TRAFFIC JAMS } \\
\hline No & Reference & & \\
\hline Yes & 0.091 & 0.086 & 0.096 \\
\hline \multicolumn{4}{|l|}{ SAMPLER HEIGHT } \\
\hline First floor & Reference & & \\
\hline Ground floor & -0.031 & -0.040 & -0.021 \\
\hline Second floor & 0.001 & -0.021 & 0.023 \\
\hline \multicolumn{4}{|l|}{ STREET EDGE DISTANCE } \\
\hline $0-2 m$ & Reference & & \\
\hline $2-5 m$ & -0.049 & -0.055 & -0.044 \\
\hline $5-10 m$ & -0.076 & -0.081 & -0.071 \\
\hline$>10 m$ & -0.109 & -0.115 & -0.103 \\
\hline \multicolumn{4}{|l|}{ TREES IN THE STREET } \\
\hline No trees & Reference & & \\
\hline Sparse tree coverage & -0.013 & -0.017 & -0.009 \\
\hline Dense tree coverage & -0.013 & -0.019 & -0.007 \\
\hline \multicolumn{4}{|l|}{ HOUSING TYPE } \\
\hline Detached & Reference & & \\
\hline Semi-detached & 0.036 & 0.031 & 0.041 \\
\hline Terraced & 0.107 & 0.101 & 0.113 \\
\hline \multicolumn{4}{|l|}{ StREET CANYON } \\
\hline $\begin{array}{l}\text { No } \\
\text { Yes }\end{array}$ & Reference & 0057 & 0 O65 \\
\hline \multicolumn{4}{|l|}{ Model performance } \\
\hline Spatial variation $\sigma_{u}^{2}$ & 0.0057 & 0.0048 & 0.0064 \\
\hline Residual variation $\sigma_{\varepsilon}^{2}$ & 0.013 & 0.012 & 0.013 \\
\hline Range (metre) & 7397 & 6403 & 8448 \\
\hline
\end{tabular}

Extended Data Table 3. Posterior regression coefficients for a Bayesian geospatial regression on log-transformed $\mathrm{NO}_{2}$ levels. The mean and $95 \%$ confidential intervals of the regression coefficients are shown, alongside the residual variation and random spatial variation. Land Use and Street Type are based on Open Street Map (OSM) Typology. 
"Farming" combines the OSM land use categories farm, meadow and orchard; "Greenspace" combines the OSM land use categories cemetery, forest, grass, heath, nature_reserve, park, recreation_ground, and scrub. The range denotes the distance at which the spatial variance becomes less than $10 \%$. 


\begin{tabular}{l|c|c|c|c|}
\hline $\begin{array}{l}\text { Model performance } \\
\text { statistic }\end{array}$ & Units & $\begin{array}{c}\text { ATMO-Street } \\
\text { (old) }\end{array}$ & $\begin{array}{c}\text { ATMO-Street } \\
\text { (new) }\end{array}$ & $\begin{array}{c}\text { Geospatial } \\
\text { model }\end{array}$ \\
\hline Bias & $\left(\mu \mathrm{g} / \mathrm{m}^{3}\right)$ & -4.1 & -2.7 & -0.17 \\
RMSE & $\left(\mu \mathrm{g} / \mathrm{m}^{3}\right)$ & 6.1 & 5.2 & 3.1 \\
BCRMSE & $\left(\mu \mathrm{g} / \mathrm{m}^{3}\right)$ & 4.6 & 4.4 & 3.1 \\
R2 & - & 0.58 & 0.54 & 0.76 \\
MQI & - & 1.00 & 0.88 & - \\
F2 & - & 0.97 & 0.99 & - \\
\hline
\end{tabular}

Extended Data Table 4. Overview of the model performance statistics after data-model comparison of the ATMO-Street ("old" = before model improvement and "new" = after model improvement) and the Bayesian Geospatial models. RMSE = Root Mean Square Error, BCRMSE = Bias-Corrected Root Mean Square Error, R2 = coefficient of determination, MQI $=$ FAIRMODE Model Quality Indicator, F2 = Similarity Factor. 


\begin{tabular}{|c|c|c|}
\hline Model type & $\begin{array}{c}\text { RMSE } \\
\text { 4 samplers } \\
\left(\boldsymbol{\mu g} / \mathbf{m}^{3}\right)\end{array}$ & $\begin{array}{c}\text { RMSE } \\
\text { 2 samplers } \\
\left(\boldsymbol{\mu g} / \mathbf{m}^{3}\right)\end{array}$ \\
\hline Orthogonal regression & 1.97 & 2.21 \\
Intercept & 1.95 & 2.15 \\
Ratio & 2.44 & 2.54 \\
\hline
\end{tabular}

Extended Data Table 5. Model uncertainty for three different model examined dutrinf calibration. RMSE = Root Mean Square error. 


\begin{tabular}{l|c|c}
\hline Model & DIC & WAIC \\
\hline Intercept + spatial, lognormal & 128080 & 125060 \\
Intercept + covariates, lognormal & 89841 & 89846 \\
Intercept + covariates + spatial, lognormal & 84609 & 84555 \\
Intercept + covariates + spatial, gamma & 84896 & 84889 \\
\hline
\end{tabular}

Extended Data Table 6. DIC and WAIC for models including and excluding covariates and spatial structure. 


\section{Extended data figures}
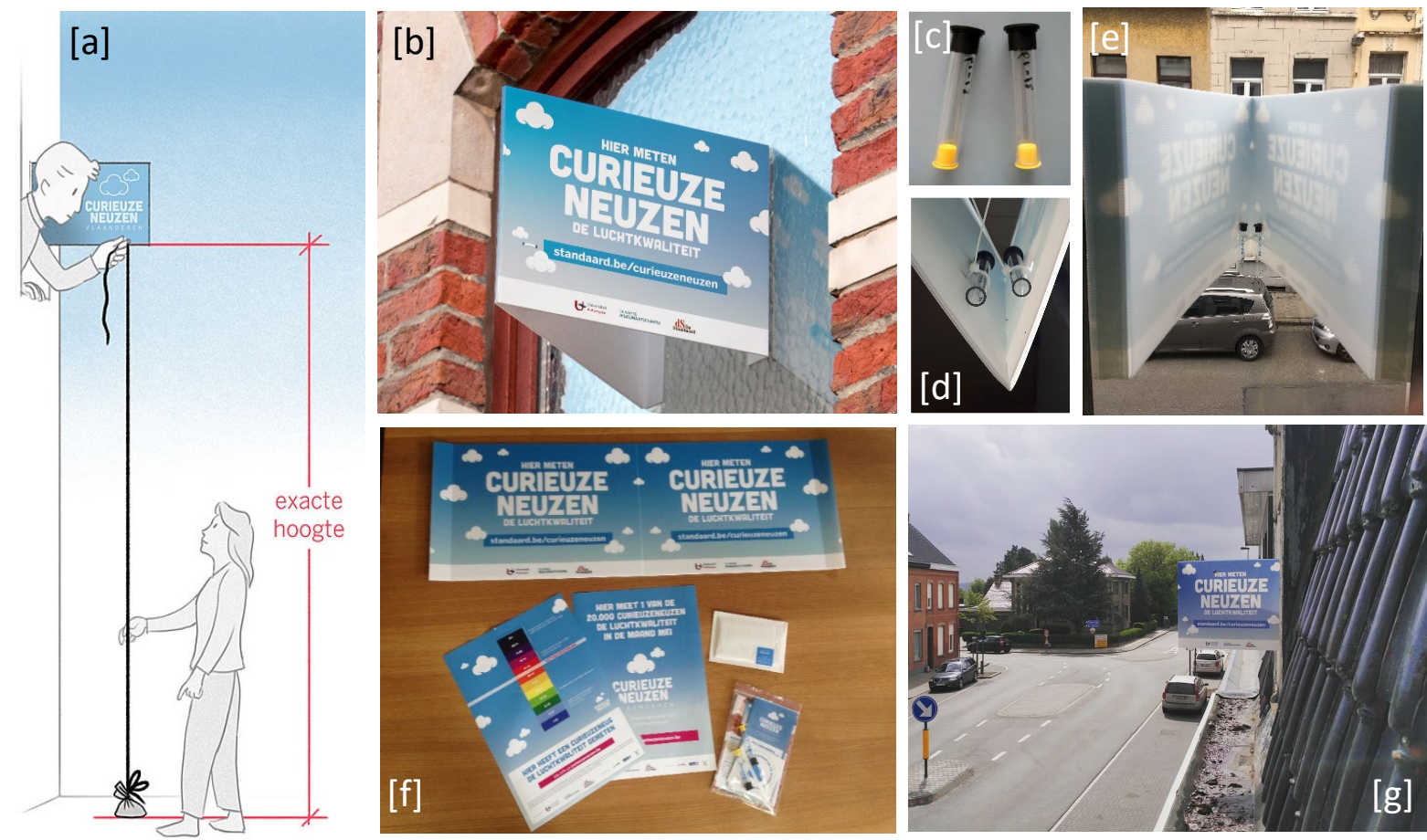

Extended Data Figure 1. Measurement setup for ambient $\mathrm{NO}_{2}$ as implemented in the CurieuzeNeuzen Vlaanderen citizen science project. [a] The height was measured using a simple procedure and supplied as supporting data by the participants. [b-e] Operator variability was reduced through a standardized setup by attaching two passive samplers in the nose of a real estate panel. [f] The sampling kit included two samplers, the panel, an instruction manual, a return envelope for the samplers, and two posters for communication with neighbours. [g] Measurement panels were attached to a window on the first floor facing the street. 


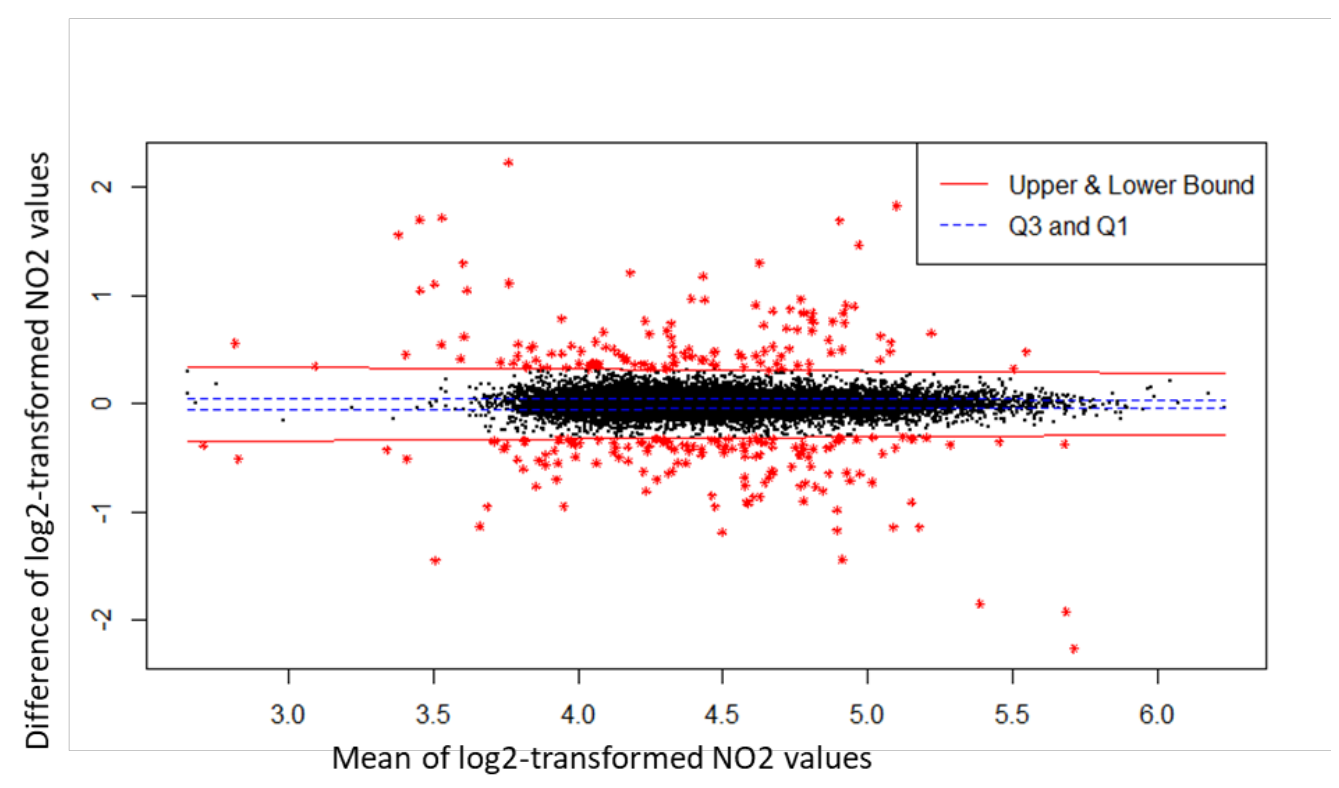

Extended Data Figure 2. Outlier detection through quantile regression. The x-axis denotes the mean of the log2 transformed $\mathrm{NO}_{2}$ value from the two duplicate passive samplers at each measurement location. The $\mathrm{y}$-axis denotes the difference of the log 2 transformed $\mathrm{NO}_{2}$ value from the two duplicate passive samplers. The blue lines denotes the interquartile range (Q1 and Q3). The red lines represent the thresholds for outlier detection. All data points outside of these red lines are considered outliers (indicated by red markers). 


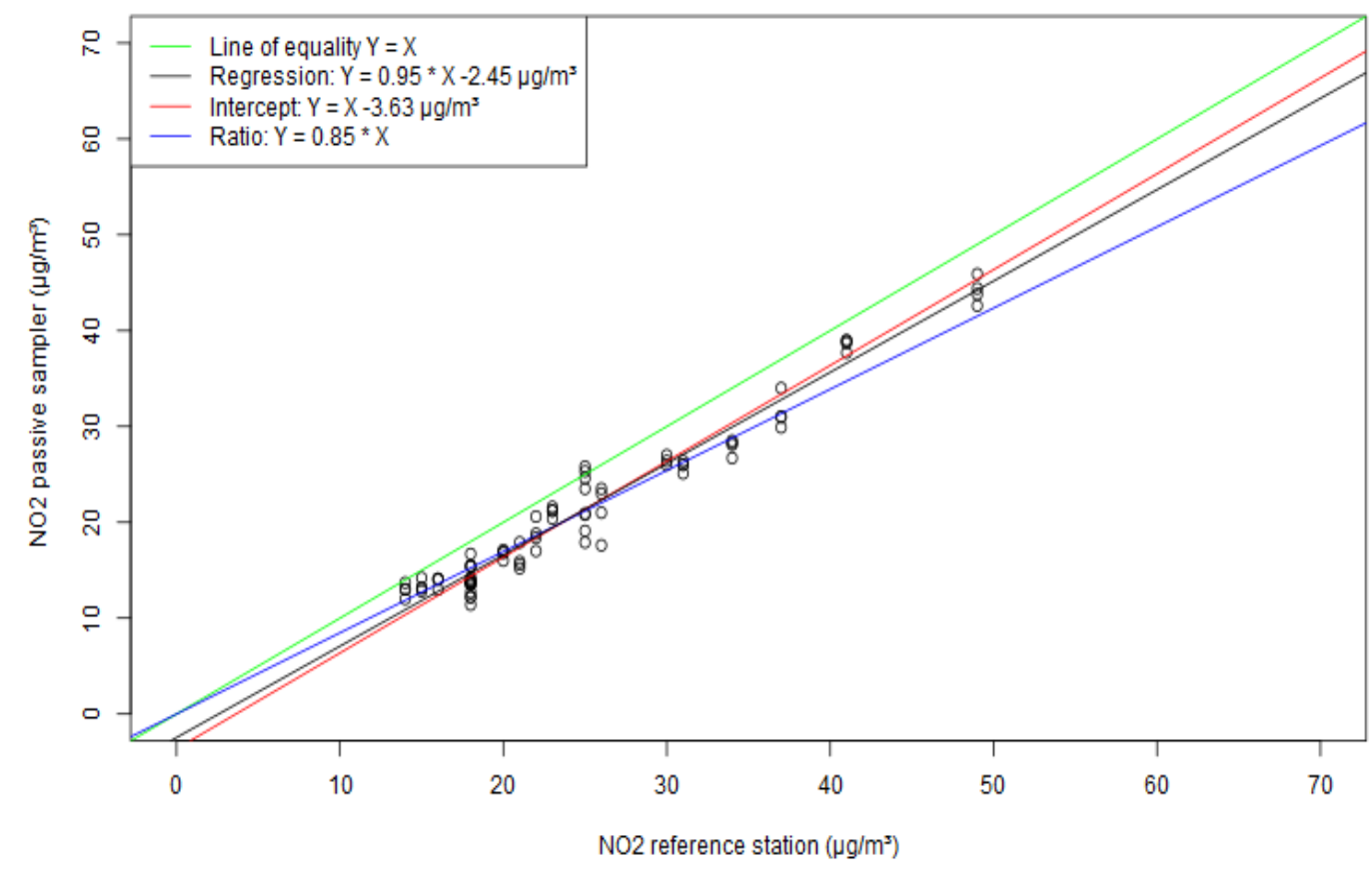

Extended Data Figure 3. Co-deployment of passive samplers at 20 reference stations. The $x$-axis denotes the reference data $X_{i}$, which represent the mean $\mathrm{NO}_{2}$ concentration over the 4 week period measured by chemiluminescence at the reference stations. The $y$-axis denotes the sampler data $\mathrm{Y}_{i}$, which represent the mean $\mathrm{NO}_{2}$ concentration as determined by the 4 passive samplers that were co-located at the reference stations. The 1:1 line (green) as well as the best fitting trend lines for three separate models are shown. 


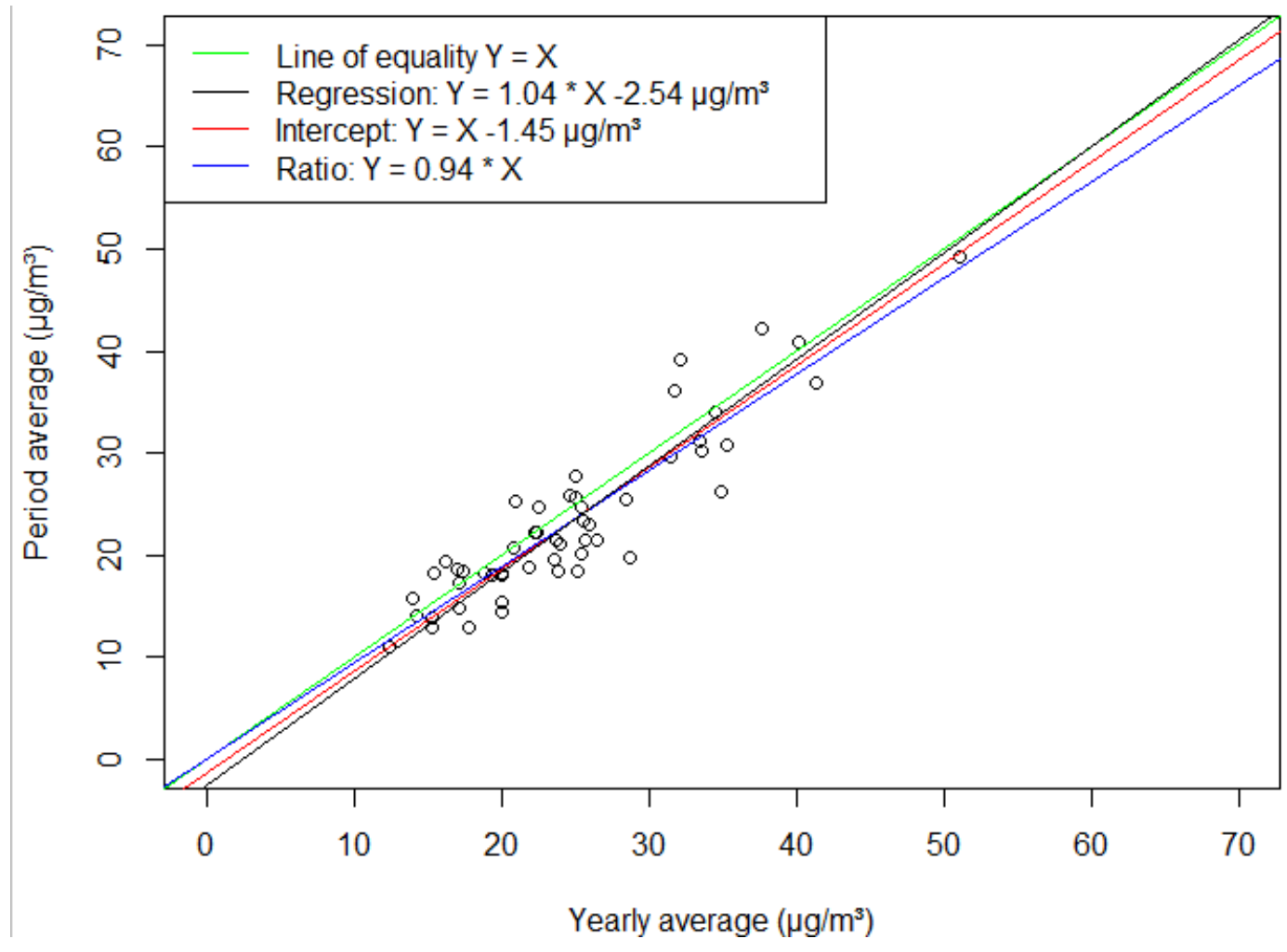

Extended Data Figure 4. Transformation of monthly mean $\mathrm{NO}_{2}$ values to annual mean $\mathrm{NO}_{2}$ values. graph. The $\mathrm{x}$-axis denotes the mean $\mathrm{NO}_{2}$ concentration over the 4 week period as measured by chemiluminescence at the reference stations. The $y$-axis denotes denotes the annual mean $\mathrm{NO}_{2}$ concentration (over 1 year period encompassing the measurement period: April 2017-May 2018) as measured by chemiluminescence at the same reference stations. The 1:1 line (green) as well as the best fitting trend lines for three separate models are shown. 


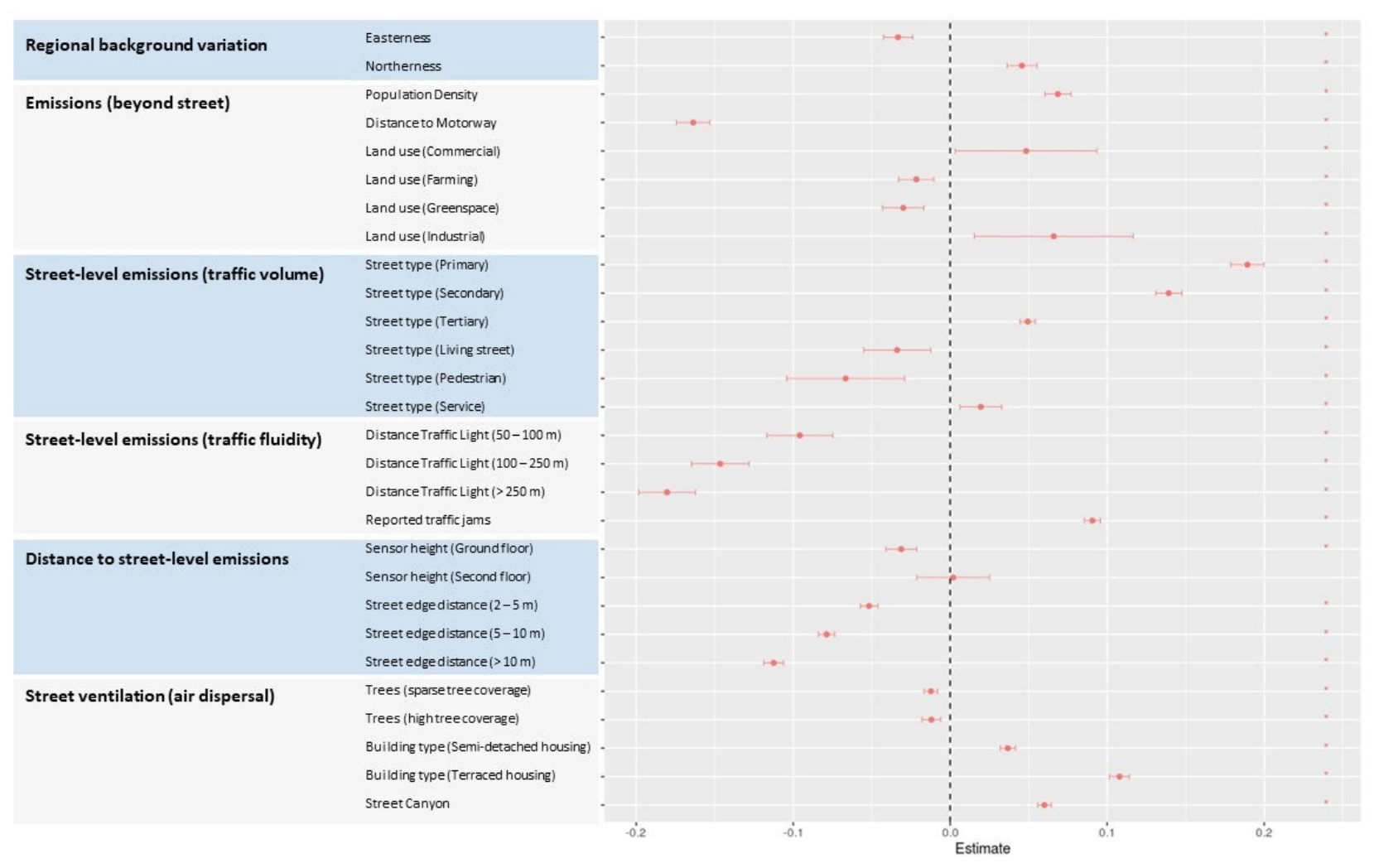

Extended Data Figure 5. Summary of the Bayesian geospatial model results. Continuous covariates were standardised prior to inclusion in the model. $\mathrm{NO}_{2}$ concentrations showed a broad geographical trend across the region, increasing from East to West and South to North. A significant positive association is observed between annual $\mathrm{NO}_{2}$ concentrations and population density, while the distance away from motorway was negatively correlated with $\mathrm{NO}_{2}$ levels. "Commercial" and "Industrial" land use types displayed significantly higher pollution levels as "Residential", which acted as the reference, while "Farming" and "Greenspaces" scored significantly lower. At the street level, "Pedestrian" and "Living street" categories had lower $\mathrm{NO}_{2}$ levels compared to residential, while "Primary", "Secondary" and "Tertiary roads" had higher levels. $\mathrm{NO}_{2}$ decreased significantly with distance from traffic lights and from street edge, and was lowest on ground level. $\mathrm{NO}_{2}$ levels increased where participants reported traffic jams, and was higher in street canyons and around terraced houses. Tree coverage reduced $\mathrm{NO}_{2}$ pollution levels. 


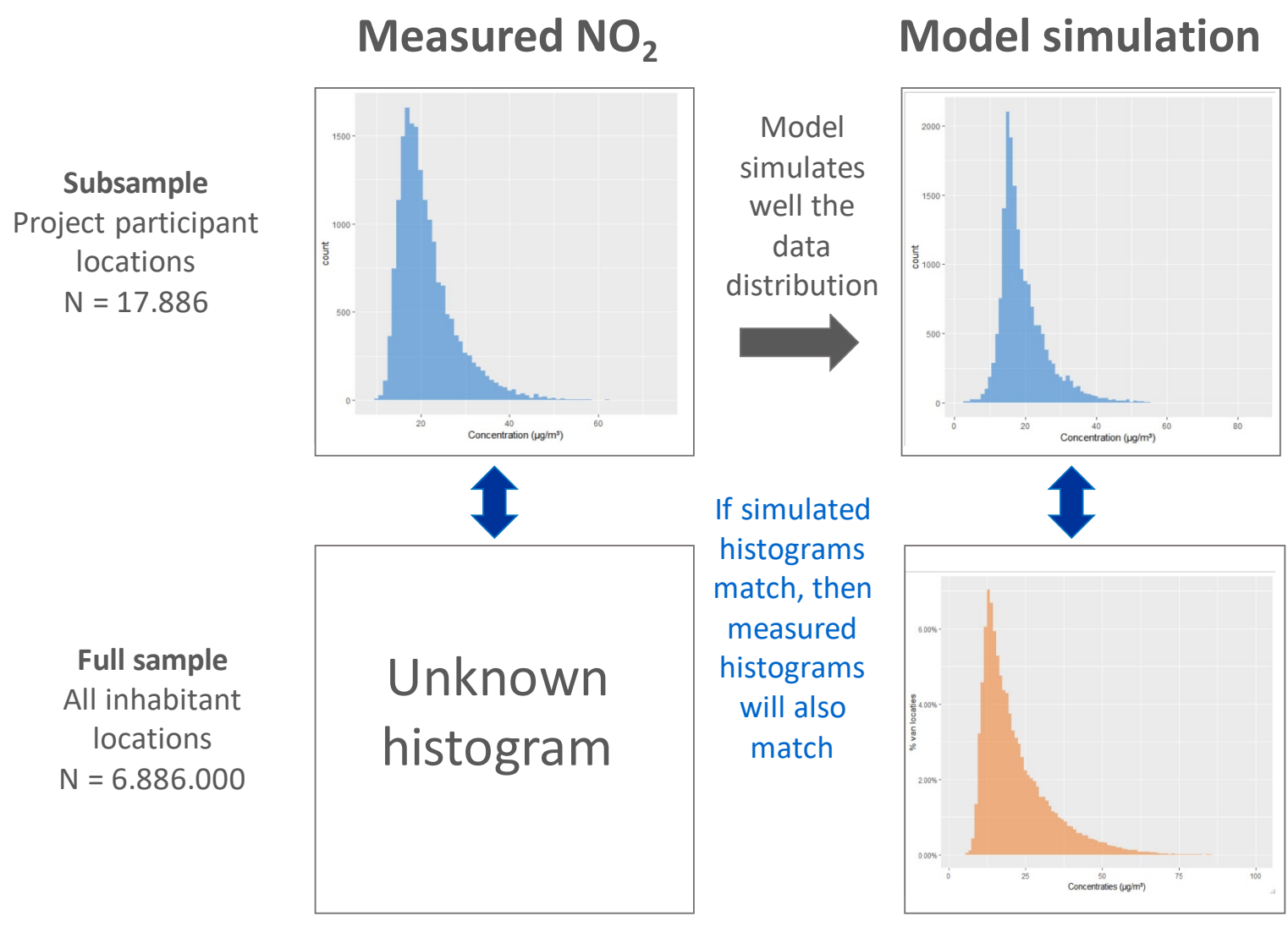

Extended Data Figure 6. Verification procedure of the representativeness of the sampling location selection for the population of Flanders as a whole. The frequency distribution of $\mathrm{NO}_{2}$ concentrations at all home locations in Flanders is unknown. We compare the frequency distribution of (i) the measured $\mathrm{NO}_{2}$ concentration at the main house entrance for each participant in the CurieuzeNeuzen project (ii) the model-simulated $\mathrm{NO}_{2}$ concentration measured at the main house entrance for each participant in the CurieuzeNeuzen project, and (iii) the model-simulated $\mathrm{NO}_{2}$ concentration measured at the main house entrance for each inhabitant in Flanders. 

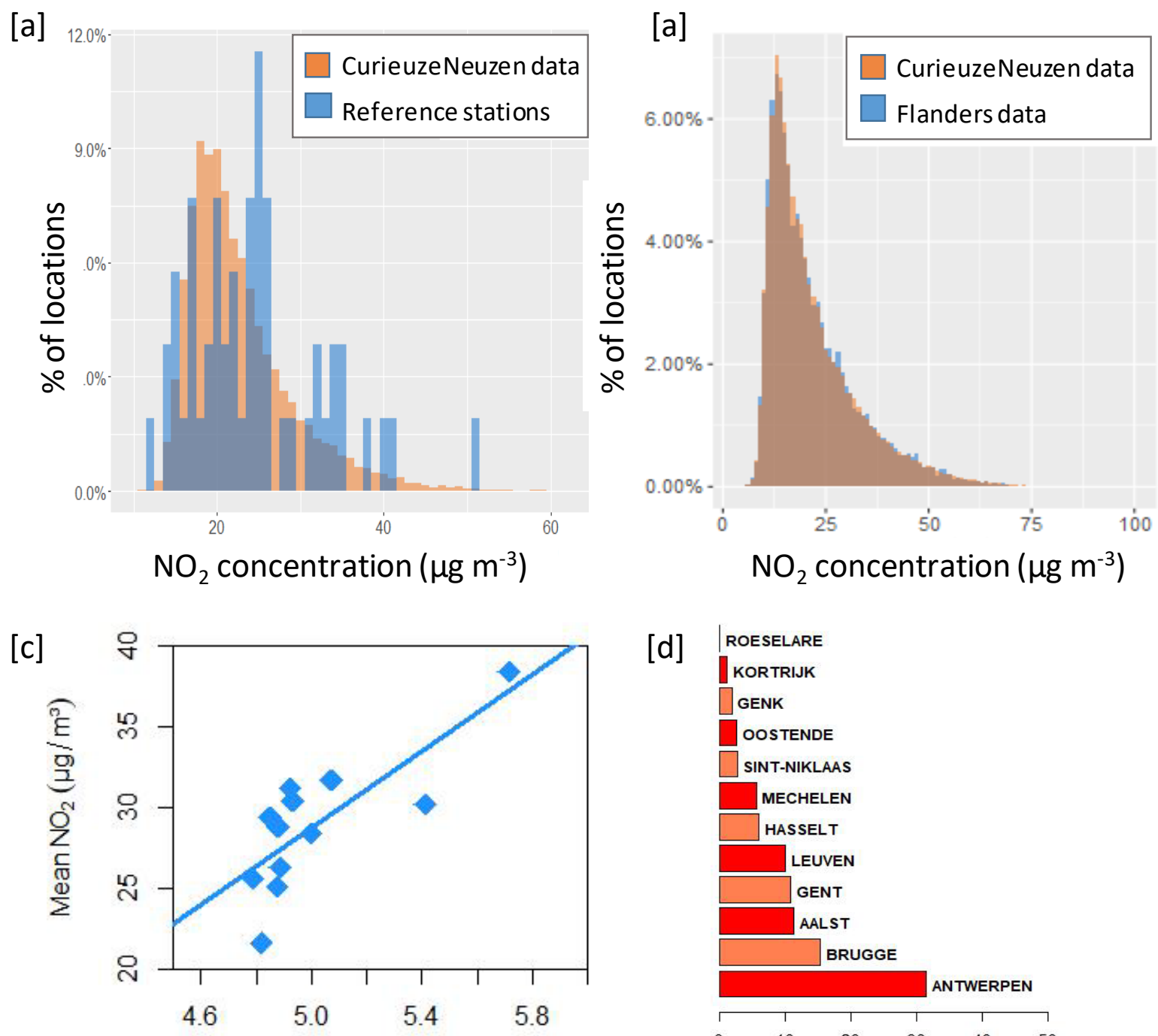

Population size $(\log 10)$

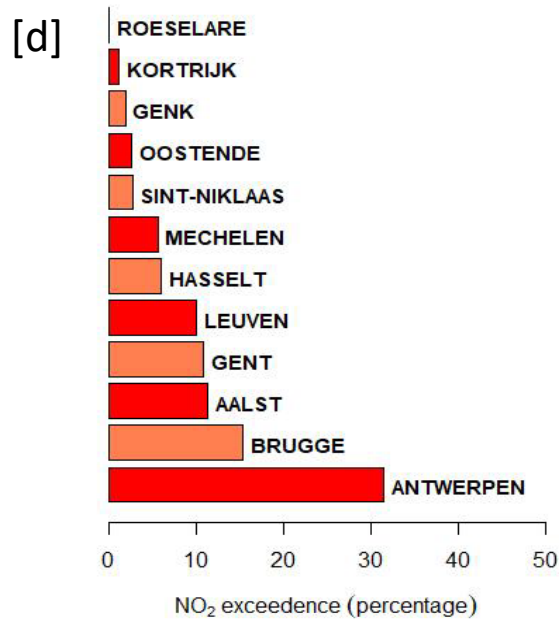

Extended Data Figure 7. [a] Comparison of the frequency distribution of $\mathrm{NO}_{2}$ at the sampling locations in the CurieuzeNeuzen project (orange) with the sparse data from the official reference monitoring network. Mean $\mathrm{NO}_{2}$ concentrations over the 4-week campaign period are depicted. [b] Comparison of the frequency distribution of simulated $\mathrm{NO}_{2}$ concentrations at the sampling locations of the CurieuzeNeuzen project (orange) with the simulated $\mathrm{NO}_{2}$ concentrations at the frontdoor location of all inhabitants in Flanders (blue). Both frequency distributions are highly similar, indicating the representativeness of the CurieuzeNeuzen dataset in terms of residential exposure. [c] Plot of the mean annual $\mathrm{NO}_{2}$ concentration as a function of the population size for all towns $>50,000$ inhabitants. [d] Percentage of sampling points in the city centre exceeding the EU limit value of $40 \mu \mathrm{g} \mathrm{m}^{-3}$ for all towns $>50,000$ inhabitants. 

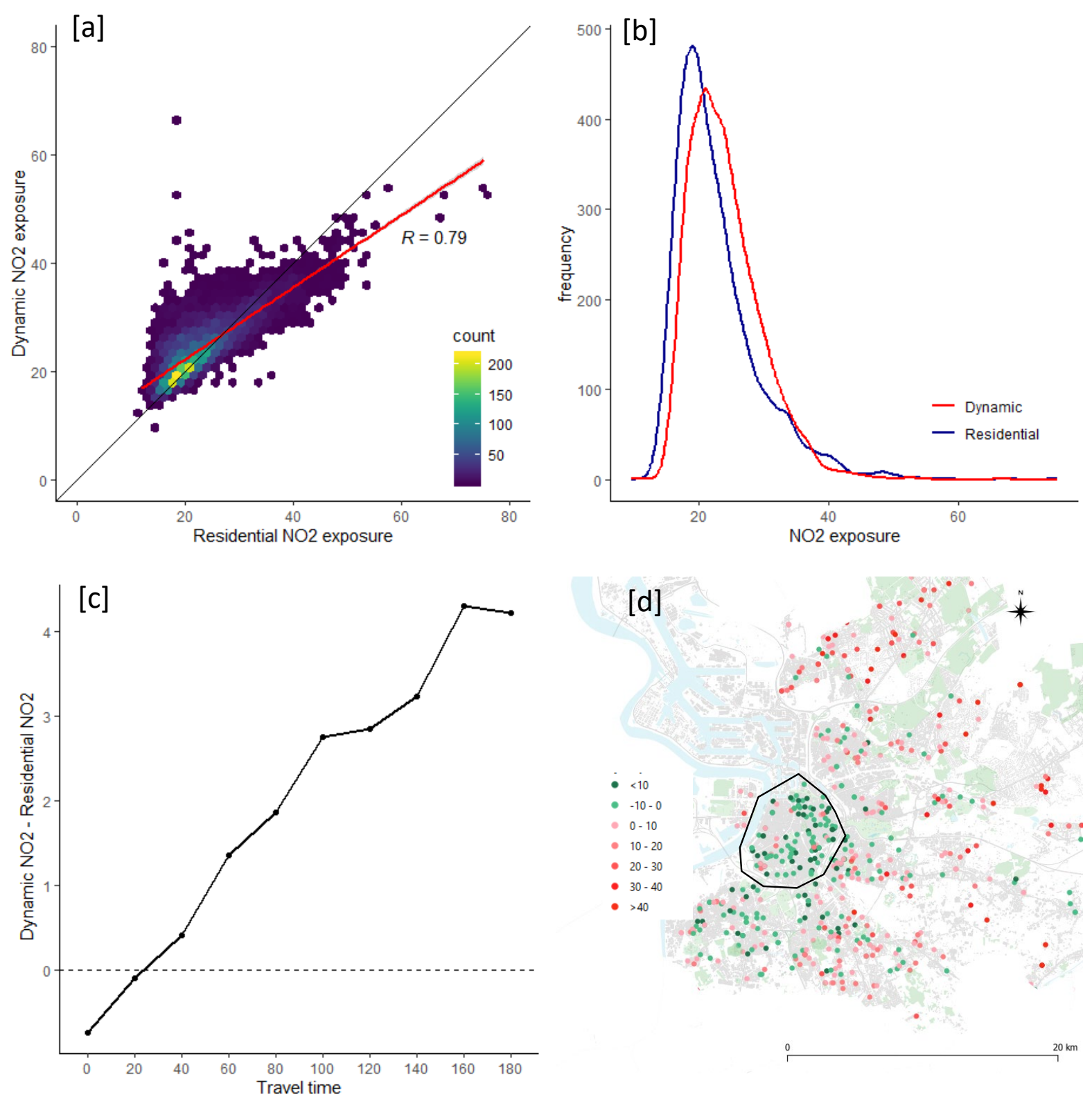

Extended Data Figure 8. Residential versus dynamic $\mathrm{NO}_{2}$ exposure in $\mu \mathrm{g} \mathrm{m}^{-3}$. [a] Scatter plot with hexagonal binning. [b] Distribution of residential and dynamic $\mathrm{NO}_{2}$ exposure (mean annual $\mathrm{NO}_{2}$ concentration). [c] Difference between dynamic and residential exposure as a function of travel time (daily travel time in minutes as predicted by the Google Directions API). [d] Relative difference between dynamic and static $\mathrm{NO}_{2}$ exposure (\% difference). The map shows the city centre of Antwerp (solid line), the largest city in Flanders, and surrounding suburban areas. Participants living in the city centre generally have a lower dynamic exposure compared to their residential exposure, while for individuals living in suburban and rural areas the dynamic exposure is generally higher. 

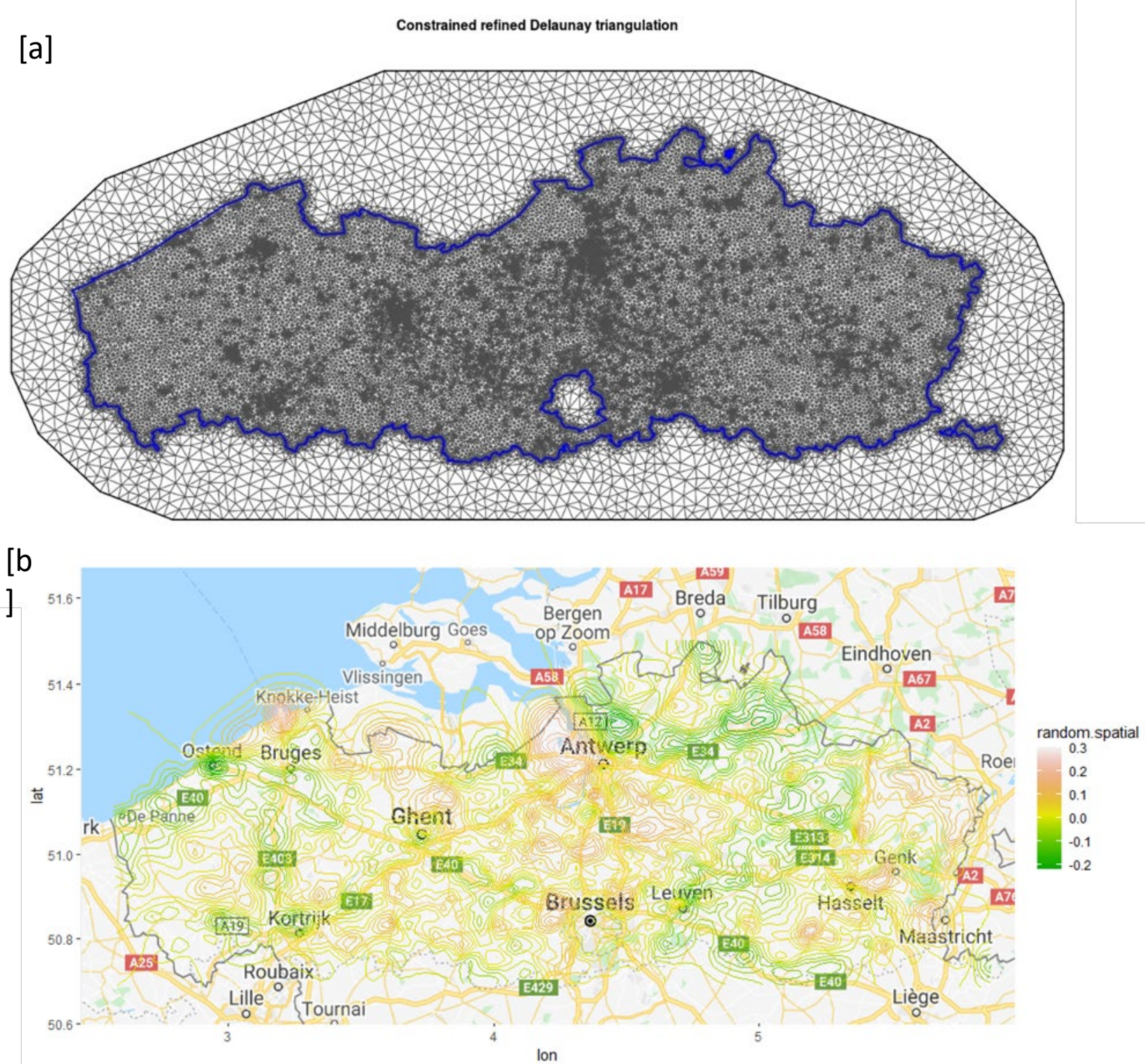

Extended Data Figure 9. [a]. Constrained defined Delaunay triangulation, covering the domain of Flanders (Belgium), as used in the R-INLA procedure of the Bayesian geospatial modelling. [b] Summary of the spatial random effect (Gaussian random field), providing information on spatial variance that is not captured by the Bayesian geospatial model. The seaport near Bruges and the shipping channel Gent-Terneuzen display $\mathrm{NO}_{2}$ pollution that is not accounted for, suggesting that the inclusion of distance to shipping emissions as a cofactor would enhance the model. 